\title{
Fragmentation Model of the Grain Size Mix of Sediment Supplied to Basins
}

\author{
Philip A. Allen, ${ }^{1, \star}$ John J. Armitage, ${ }^{2}$ Alexander C. Whittaker, ${ }^{1}$ Nikolaos A. Michael, ${ }^{3}$ \\ Duna Roda-Boluda, ${ }^{1}$ and Mitchall D'Arcy ${ }^{1}$
}

1. Department of Earth Science and Engineering, Imperial College, South Kensington Campus, London SW7 2AZ, United Kingdom; 2. Department of Earth Sciences, Royal Holloway College, University of London, Egham, Surrey TW20 OEX, United Kingdom; 3. Geological Technology Team Division, Exploration and Petroleum Engineering Center-Advanced Research Center (EXPEC ARC), Saudi Aramco, Dhahran 31311, Saudi Arabia

\begin{abstract}
A B S T R A C T
A key factor in the downstream dispersal and fractionation of sediment is the grain size distribution of sediment supplied by upstream catchments. Modeling of the grain size distribution of modern bedload in the main trunk channels of tectonically uplifting catchments, including the sediment at their outlets, and the weathering products of a range of bedrock lithologies in southern Italy and Sicily reveals fractal dimensions of 2.3-2.7, similar to the fractal dimension of many natural materials undergoing fragmentation. We examine the impact of changing statistical properties of the grain size distribution of the sediment supply in simulating grain size trends in sedimentary basins. Model simulations show a marked movement of the gravel front and patterns of progradation and retrogradation in basin stratigraphy. These grain size trends and sedimentary architectures are generated simply by variations in the grain size mix of the sediment supply, without variations in base level or sediment discharge. Variation in the grain size distribution of the sediment supply may therefore act as a first-order control on sequence stratigraphic architectures in sedimentary basins.
\end{abstract}

\section{Introduction}

The cascade of sediment from source to sink begins with the release of sediment of mixed grain size from upland catchments. Although it has been proposed that different distributions of grain size in the sediment supply to basins impacts the pattern of downstream fractionation-most recently by Strong et al. (2005), Fedele and Paola (2007), Duller et al. (2010), Whittaker et al. (2010), Armitage et al. (2011), Michael et al. (2013, 2014), and Schlunegger and Norton (2015) - little is known about the characteristics of and the controls on the grain size mix serving as an initial condition for down-system dispersal.

The formation of sediment from parent rocks is part of a general process of fragmentation (Hartmann 1969; Turcotte 1997; Smalley et al. 2005). Fragmentation may result from surface impact by extra-

Manuscript received January 13, 2015; accepted July 2, 2015; electronically published October 2, 2015.

* Author for correspondence; e-mail: philip.allen@imperial .ac.uk terrestrial objects and other projectiles /Curran et al. 1977; Fujiwara et al. 1977), subsurface nuclear detonations (Schoutens 1979), fault movement causing comminution in a fault gouge or zone of cataclasis (Sammis and Steacy 1995; Billi and Storti 2004), fracturing and jointing (Barton and LaPointe 1995), and volcanic activity generating pyroclastic material, such as ash and pumice (Hartmann 1969; Kaminski and Jaupart 1998), as well as a range of industrial practices, such as the blasting, grinding, milling, and crushing operations in mining and mineral processing. However, the most important process of fragmentation in the present context is the breakdown of parent rocks by the processes of weathering $(\mathrm{Wu}$ et al. 1993; Bitelli et al. 1999; Wells et al. 2008). Weathering is an example of fragment size reduction, resulting in soils, sediment, and regolith containing fine-grained particles (Jefferson et al. 1997). This process of fragment size reduction, or comminution, is well known to result in fractal distributions of grain size (Hyslip and Vallejo 1997).

[The Journal of Geology, 2015, volume 123, p. 405-427] (c) 2015 by The University of Chicago. All rights reserved. 0022-1376/2015/12305-0002\$15.00. DOI:10.1086/683113 
The nature of the breakdown of parent rocks by the range of processes involved in mechanical weathering depends on the parent rock being fully specified in terms of its mechanical properties, which is possible only in laboratory experiments. Consequently, if the grain size distribution of the sediment released into the cascade from source to sink (Burt and Allison 2010) is to be modeled in a geomorphic context, it is necessary to account for the combined effects of parent rock lithology and microstructure, topography, climate, and the passage of time on the fragmentation process. However, in the context of geologic sediment routing systems, the range of controls on the particle size distribution of sediment exported to sedimentary basins needs to be reduced to as few parameters as possible so that the method can be used when little is known about the contributing catchment areas, including their location, size, morphometry, climate, and lithologic makeup (Somme et al. 2009).

In this contribution, we review the fractal properties of natural materials that are thought to have undergone fragmentation and derive the fractal dimension from field observations of sediment and regolith that approximates that exported from upland catchments as part of the cascade to sedimentary basins. Fractal dimensions can be converted to the shape factor of the Pareto distribution, which is thought to be a probability distribution characteristic of fractals (Mandelbrot 1966; Crovelli and Barton 1993), from which the mean grain size can be calculated. The clear role played by variations in the distribution of grain size in the supply is seen in numerical simulations of the down-system dispersal of sediment. In one set of simulations, we use a source sediment specified by the scale and shape parameters of a Pareto distribution and an exponential Sternberg-type dispersal model. In a second set, we specify the source sediment by the ratio of its standard deviation and mean derived from field data and use the self-similar solution proposed by Fedele and Paola (2007) for the down-system trend in mean grain size. Building an understanding of the impact of the changing distribution of grain size is vital for prediction of subsurface sedimentary architectures, gross depositional environments, and sedimentary facies (Strong et al. 2005; Michael et al. 2013,2014 ) and forms a key element in the fields of sequence stratigraphy and basin analysis.

\section{Fragmentation and Fractal Statistics of Natural Materials}

If a parent rock breaks into smaller pieces, which themselves break into smaller pieces and so on, we should expect the number of fragments $N$ with a size greater than a certain linear dimension $x$ to decrease as the linear dimension increases. The number of fragments with a linear dimension greater than $x$ can be expressed by the fractal number relation

$$
N(X>x)=C x^{-D_{\mathrm{f}}},
$$

where $D_{\mathrm{f}}$ is the fractal dimension associated with fragmentation and $C$ is a coefficient. $D_{\mathrm{f}}$ is typically between 2 and 4 for a range of fragment types over 4-5 orders of magnitude of $x$ (table 1; fig. 1). The number of fragments can be substituted by the volume or mass of sediment with particle sizes greater than a certain linear dimension to enable comparison with empirical plots of grain size distribution derived from sieving (Tyler and Wheatcraft 1992; Hyslip and Vallejo 1997). In such a case, equation (1) is modified from its number-specific form to a weight-specific form:

$$
P(X<x)=\frac{M(X>x)}{M_{\mathrm{T}}}=\left(\frac{x}{x_{\max }}\right)^{m},
$$

where $P$ is the proportion by weight of particles smaller than the sieve size $x, M$ is the weight (or mass) smaller than the sieve size, $M_{\mathrm{T}}$ is the total weight of sediment sieved, $x_{\max }$ is the maximum sieve or screen size (through which all particles pass), and $m$ is an index of the spread of the particle size distribution given by the slope of the power law represented by equation (1). Since particle volume or weight is related to the cube of particle number (Turcotte 1997), the parameter $m$ is related to the fractal dimension by

$$
D_{\mathrm{f}}=3-m \text {. }
$$

Using equation (1), it can be seen that when the grain size distribution is heavily loaded with fine particles the fractal dimension is large and that when the grain size distribution is loaded with coarse particles the fractal dimension is small.

The fragmentation of a fractal cube in which diagonally opposed cube-shaped blocks are retained while others are fragmented (Sammis et al. 1987) gives cumulative statistics with a fractal dimension of 2.6, and the derived fractal dimension measured in fault gouges that have undergone comminution is very close to this theoretical value (Sammis et al. 1987; Barton and LaPointe 1995; fig. 1). A range of 2.1-2.8 (clustered around 2.5) was found in a 26-mthick fault zone of cataclasis of carbonate rocks (Billi and Storti 2004), indicating a predominance of comminution. Similar comminution processes in subglacial sediment under the weight of an overlying 
Table 1. Fractal Dimensions for the Particle Size of a Range of Fragmented Natural Materials, Modified and Supplemented from Turcotte (1997; Table 3.2, p. 44)

\begin{tabular}{lcl}
\hline Material & Fractal dimension $D_{\mathrm{f}}$ & \multicolumn{1}{c}{ Source } \\
\hline Disaggregated gneiss & 2.13 & Hartmann 1969 \\
Disaggregated granite & 2.22 & Hartmann 1969 \\
Laboratory comminution of sand & $2.2-2.6$ & Lu et al. 2003 \\
& $2.3-2.6$ & Langroudi et al. 2014 \\
Fault gouge & 2.60 & Sammis and Biegel 1989 \\
Cataclastic carbonate (31 samples) & $2.1-2.9$ & Billi and Storti 2004 \\
Soils & 2.80 & Wu et al. 1993 \\
Gravelly and sandy soils (52 samples) & $2.72-2.78$ & Hyslip and Vallejo 1997 \\
Semiarid soils & $2.92-3.25$ & Martinez-Mena et al. 1999 \\
Temperate soils & $2.15-2.24$ & Martinez-Mena et al. 1999 \\
Terrace sands and gravels & 2.82 & Hartmann 1969 \\
Loamy soils & $3.01-3.42$ & Tyler and Wheatcraft 1989 \\
Loess (quartz silt) & $2.15-2.71$ & Hou et al. 2009 \\
Glacial tills (69 samples) & $2.4-3.4$ & Benn and Gemmell 2002 \\
Glacial till & 2.88 & Hartmann 1969 \\
Subglacial tills (3 samples) & $2.84-2.96$ & Hooke and Iverson 1995 \\
Debris flow (California) & 2.8 & Hooke and Iverson 1995 \\
Ash and pumice & 3.54 & Hartmann 1969 \\
Ash falls and ash flows (62 samples) & $2.9-3.9$ & Kaminski and Jaupart 1998 \\
Mud aggregates & $2.0-2.25$ & Tambo and Watanabe 1979; \\
Asteroids and meteorites & $2.48-2.51$ & Kranenburg 1994 \\
Note. & Dohnanyi 1969; Hellyer 1971 \\
\hline
\end{tabular}

Note. In general, the higher the fractal dimension, the higher the relative percentage of fine grains in the size distribution of the material (Tyler and Wheatcraft 1992; Bitelli et al. 1999). Multiple fractal dimensions may be necessary to describe soils with clay contents of $>10 \%$ (Posadas et al. 1997).

glacier have also been invoked (Hooke and Iverson 1995). However, a fractal analysis of 69 tills and other types of glacial debris revealed a wide spread of 2.4-3.4 for the fractal dimension, with much of the variation thought to be caused by differences in parent lithology rather than reflecting the fragmentation process (Benn and Gemmell 2002).

Martinez-Mena et al. (1999) investigated the fractal dimension of the fragments in various soils from a range of climatic settings. The fractal dimension ranged widely, from 2.92-3.25 for semiarid soils to 2.15-2.24 for temperate soils. A variety of loamy soils provided high fractal dimensions in the range of 3.01-3.42 (Tyler and Wheatcraft 1989), reflecting the high proportion of fine particles generated by comminution. An analysis of 52 gravelly and sandy soils gave an average fragmentation fractal dimension of about 2.7 (Hyslip and Vallejo 1997). The loess soils that cover 10\% of Earth's surface (Pye 1995) are good examples of rock fragmentation. Analysis of classic Chinese examples gave a range of 2.15-2.71 for the fractal dimension (Hou et al. 2009). There is therefore a high degree of conformity in a wide range of soils in terms of fractal properties, but clay-rich soils may be better explained by multiple fractal dimensions rather than a single value (Posadas et al. 1997; Wang et al. 2008), since clay-grade sediment may form by processes other than fragmentation.
Since the fractal dimension indicates the spread of the grain size distribution, it is potentially a powerful way of expressing in one parameter the natural variation of the grain size mix of the sediment supply to basins at geologic time scales.

\section{Fractal Dimension of Sediments within the "Erosional Engine"}

It can reasonably be expected that the grain size distributions of sediment released from catchments will be similar to those of crushed or mechanically disintegrated materials rather than to those of sediments that have undergone profound reworking and sorting during transport. Hydraulic sorting during transport is thought to generate grain size distributions of exponential or lognormal types (McEwen et al. 1959; Middleton 1976; Ibbeken 1983; Allen et al. 2015). In this study, a number of different regolith and sediment types have therefore been analyzed that might approximate the time-averaged characteristics of the sediment efflux of upland catchments on geologic time scales. These materials include (i) bedload sediment in the main channels of the Pagliara, Fiumedinisi, and Agro catchments etched into a region of active uplift at $1-1.5 \mathrm{~mm} \mathrm{yr}^{-1}$ in northeastern Sicily; (ii) coarse sediment at the outlet points of catchments distributed along strike of topographic 


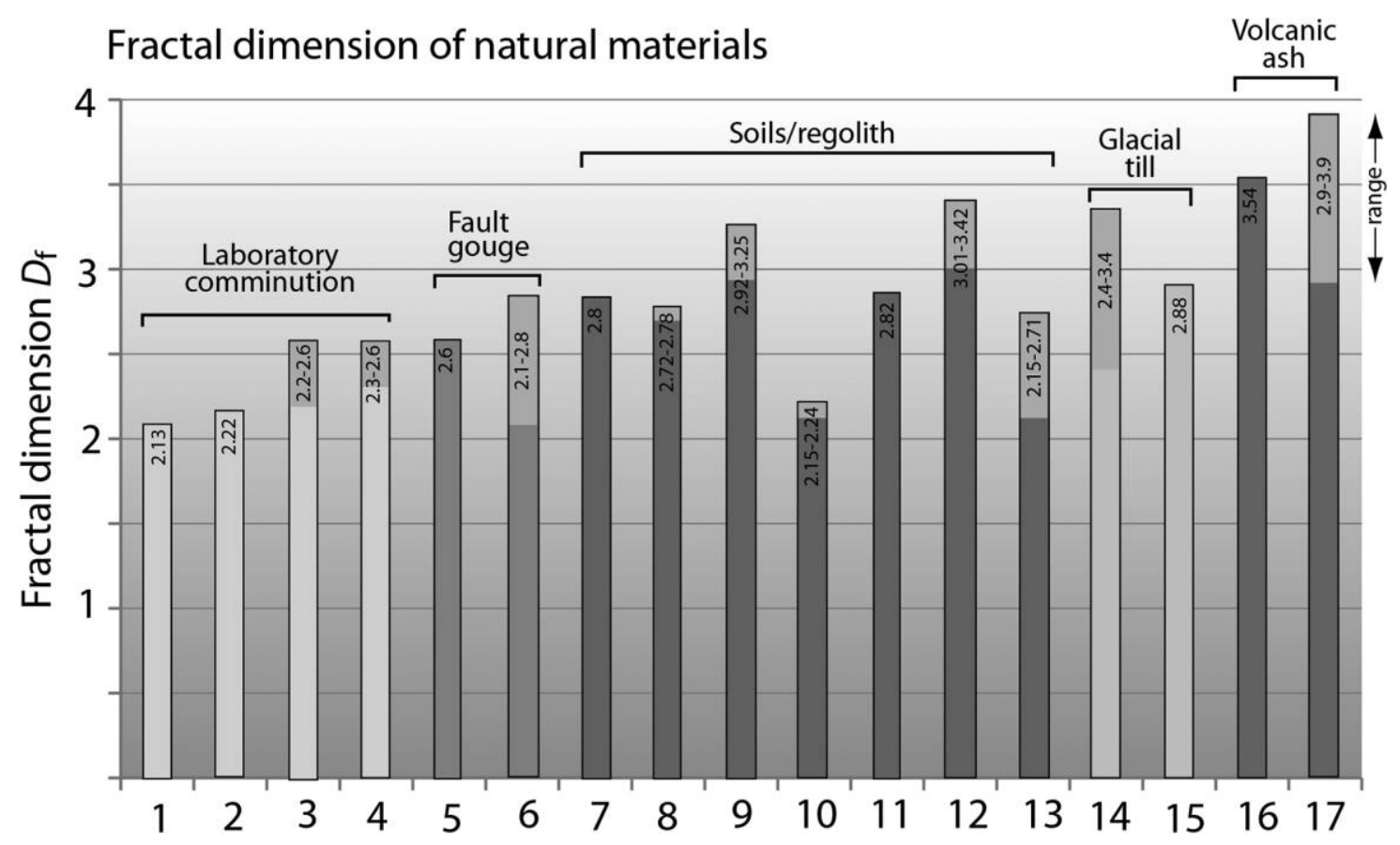

Figure 1. Average fractal dimension for a range of natural materials (rocks, soils, regolith, sediments). $1=$ disaggregated gneiss; $2=$ disaggregated granite; $3,4=$ laboratory comminution of sand; $5=$ fault gouge; $6=$ cataclastic zone; $7=$ soils $($ general); $8=52$ gravelly and sandy soils; $9=$ semiarid soils; $10=$ temperate soils; $11=$ loamy soils; $12=$ loess (quartz silt); $13=$ terrace sands and gravels; $14=69$ glacial tills; $15=$ glacial till; $16=$ volcanic ash and pumice; $17=62$ ash fall and ash flow deposits. References are in table 1 . A color version of this figure is available online.

ranges in Sicily and Basilicata-Campania, southern Italy; and (c) weathering products (regolith) in catchments in southern Italy developed on a range of different rock types. Together, these data sets provide an excellent idea of the typical fractal dimensions of sediments and regolith stored in upland catchments prior to export to sedimentary basins.

Methods. A number of different methods of grain size measurement have been used, principally sieving and Wolman clast measurement. Sediment was sieved and weighed in the field at 19 localities at catchment outlets along the strike of the topographic range front in northeastern Sicily between Taormina and Capo Milazzo (fig. 2), and it was also collected at several upstream locations in the Pagliara, Fiumedinisi, and Agro catchments (see tables 2, 3). Fine material of $<10 \mathrm{~mm}$ was bagged, weighed, and subjected to further sieving in the laboratory at Imperial College. Exceptionally coarse material was weighed in the field and measured individually to produce an estimate of average clast diameter. The largest clast was never greater than $5 \%-10 \%$ of the total sediment mass. The sieved data were used to derive cumulative frequency distributions from which estimates of intermediate axis median grain size $\left(D_{50}\right)$ and coarse-fraction grain size $\left(D_{84}\right)$ were derived. Simultaneously, the major axes of grains of $>1 \mathrm{~mm}$ were measured using the Wolman method (Wolman 1954). One hundred clasts were measured at random and the process was repeated twice, to check on reproducibility of results, so 300 clasts were measured at each locality in Sicily. Errors on $D_{50}$ estimates from this measuring strategy were 10\%$15 \%$ from repeat Wolman point counts. Long axes were measured, as it is very difficult to measure effectively the intermediate axes of small clasts of $<20 \mathrm{~mm}$; the ratio between the intermediate and long axis in smaller clasts is usually 0.8-0.9 (Krumbein 1941), which is comparable to the error in $D_{50}$ derived from repeated Wolman point counts at the same locality. Consequently, we compared the Wolman point-count data to the sieved grain size data without further correction.

The intercept of the log-log plot of $(X>X) / M_{\mathrm{T}}$ versus the normalized sieve size $x / X_{\max }$ is 0 if the size distribution is perfectly fractal. Bearing in mind the difficulty of sampling the very coarsest clasts, which may weigh more than $50 \mathrm{~kg}$, we allowed the intercept to deviate slightly from 0 to achieve better fits to the main range of grain size. Inspection of loglog plots indicates that data points for grain sizes of $<1 \mathrm{~mm}$ fall away from the linear regression, sug- 


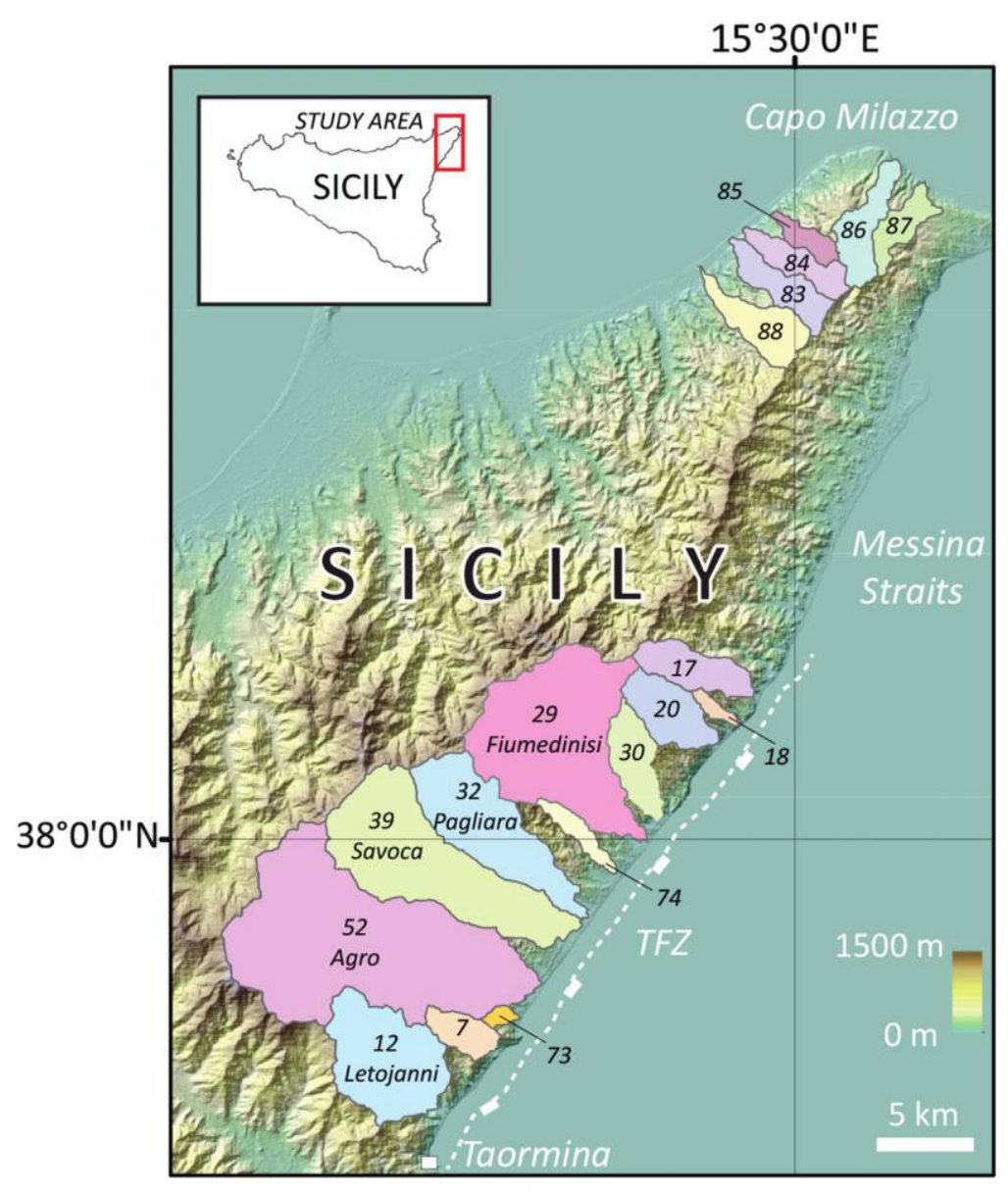

Figure 2. Hillshaded digital elevation model image showing study catchments in northeastern Sicily, Italy. Numbers refer to catchment IDs as indicated in table 2 and figure 4 . The inset shows the location of the study area with respect to the island of Sicily. TFZ $=$ Taormina normal fault zone.

gesting that these grain sizes are underrepresented relative to the fractal prediction. Statistics were therefore calculated by fitting a straight line through the remaining data points (fig. $3 A$; table 2), which improves the regression and gives more accurate values for the slope $m$. Data sets that gave regression coefficients $\left(R^{2}\right)$ of $<0.9$ were excluded from the analysis (table 2).

The results from sieved samples can be compared with the grain size distributions obtained from the Wolman method (figs. 4, 5). Clast diameters measured using the Wolman method were binned into sizes of $<5,10,20,40,80,160$, and $320 \mathrm{~mm}$ to allow the closest possible comparison with sieved data. Data series were truncated at the very coarse end, acknowledging the problems of sampling of boulders, and at the fine end for grain sizes of $<1 \mathrm{~mm}$, to improve the regression and to facilitate comparison with sieve results at the same localities (table 2).

Grain size data were also generated by sieving of the bedload material in the main channel of three
Sicilian catchments (Pagliara, Fiumedinisi, and Agro; table 3), since it is reasonable to assume that the sediment efflux of the catchment is similar in size distribution to the sediment lying in its active channels. Samples were obtained at 10, 10, and 11 stations in the Pagliara, Fiumedinisi, and Agro catchments, respectively (table 3). At each station in the downstream direction, between 100 and $300 \mathrm{~kg}$ of sediment was sieved.

The fractal dimension can be calculated in two ways. First, taking the logarithm of both sides of equation (2) gives a straight-line relationship between $M(X<x) / M_{\mathrm{T}}$ and $x / X_{\max }$ if the distribution is fractal, where the slope is $m=3-D_{\mathrm{f}}$ (eq. [3]). Equation (2) was used to determine the fractal dimension from sieve data collected at the 19 localities at the outlets of Sicilian catchments (table 2). Second, the value of the fractal dimension at each station along the main channel of three catchments in Sicily was interpolated by taking the proportion by weight at two characteristic grain sizes, $D_{84}$ and 
Table 2. Fractal Dimension $D_{\mathrm{f}}$ of Sediment Samples Collected from the Outlet Points of Eastern Sicilian Catchments along a Faulted Topographic Range Front

\begin{tabular}{|c|c|c|c|c|c|c|c|c|c|c|}
\hline \multirow[b]{3}{*}{ River name (catchment ID) } & \multirow{3}{*}{$\begin{array}{l}\text { Drainage } \\
\text { area }\left(\mathrm{km}^{2}\right)\end{array}$} & \multirow{3}{*}{$\begin{array}{l}\text { Distance along } \\
\text { strike }(\mathrm{km})\end{array}$} & \multicolumn{4}{|c|}{ All data } & \multicolumn{4}{|c|}{ Truncated } \\
\hline & & & \multicolumn{2}{|c|}{ Wolman } & \multicolumn{2}{|c|}{ Sieve } & \multicolumn{2}{|c|}{ Wolman } & \multicolumn{2}{|c|}{ Sieve } \\
\hline & & & $D_{\mathrm{f}}$ & $R^{2}$ & $D_{\mathrm{f}}$ & $R^{2}$ & $D_{\mathrm{f}}$ & $R^{2}$ & $D_{\mathrm{f}}$ & $R^{2}$ \\
\hline \multicolumn{11}{|l|}{ Taormina fault: } \\
\hline Alcantara (11) & 430 & 2.75 & 2.37 & .936 & 2.45 & .967 & 2.37 & .994 & 2.46 & .982 \\
\hline Lettojanni (12) & 27 & 11.15 & 2.36 & .849 & 2.54 & .975 & 2.48 & .987 & 2.51 & .951 \\
\hline San Filippo (72) & 6 & 13.3 & 2.56 & .953 & 2.56 & .953 & 2.18 & .979 & 2.54 & .940 \\
\hline Forza D'Agro (73) & 3 & 15.1 & 2.60 & .955 & 2.60 & .955 & 2.56 & .942 & 2.61 & .937 \\
\hline D'Agro (52) & 83 & 18.5 & 2.70 & .973 & 2.47 & .972 & 2.39 & .991 & 2.73 & .986 \\
\hline Savoca (39) & 44.5 & 21.35 & 2.59 & .789 & 2.59 & .789 & 2.08 & .984 & 2.71 & .947 \\
\hline Pagliara (32) & 27 & 22.7 & 2.61 & .780 & 2.61 & .780 & 2.36 & .968 & 2.72 & .962 \\
\hline Alume (74) & 10.75 & 24.85 & 2.55 & .934 & 2.55 & .934 & 2.48 & .975 & 2.58 & .915 \\
\hline Fiumedinisi (29) & 50 & 27.35 & 2.42 & .811 & 2.42 & .811 & 2.62 & .977 & 2.59 & .938 \\
\hline Ali (30) & 9 & 28.95 & 2.39 & .797 & 2.29 & .797 & 2.44 & .989 & 2.50 & .884 \\
\hline Itala $(20)$ & 11 & 33.25 & 2.65 & .938 & 2.65 & .938 & 2.62 & .958 & 2.69 & .947 \\
\hline Scaletta (18) & 3 & 34.85 & 2.57 & .797 & 2.57 & .797 & 2.58 & .959 & 2.68 & .828 \\
\hline San Peiolo (17) & 11 & 36.2 & 2.59 & .926 & 2.59 & .926 & 2.65 & .938 & 2.64 & .941 \\
\hline \multicolumn{11}{|l|}{ Capo Milazzo: } \\
\hline Gallo (88) & 9.86 & 1.8 & 2.75 & .913 & 2.70 & .915 & 2.74 & .997 & 2.79 & .923 \\
\hline Pelontano (83) & 8.33 & 9.0 & 2.74 & .598 & 2.74 & .598 & 2.74 & .995 & 2.87 & .957 \\
\hline Grancabella (84) & 7 & 11.7 & 2.59 & .791 & 2.27 & .949 & 2.08 & .988 & 2.70 & .945 \\
\hline Corsari (85) & 5 & 15.66 & 2.63 & .994 & 2.62 & .946 & 2.55 & .989 & 2.64 & .992 \\
\hline Tono $(86)$ & 8.69 & 35.37 & 2.68 & .972 & 2.71 & .961 & 2.67 & .979 & 2.70 & .969 \\
\hline Guideo (87) & 5.95 & 40.23 & 2.52 & .881 & 2.68 & .974 & 2.64 & .995 & 2.61 & .977 \\
\hline
\end{tabular}

Note. Fractal dimension is derived from the slope of the best-fitting linear regression of normalized weight versus size derived from wet sieving. Results are given for the Wolman and sieving methods, for all data and for data with truncation of the data series at the very coarse and fine ends, to increase the fit.

$D_{50}$, using a modification of equation (2):

$$
m=\frac{\log P\left(X<D_{84}\right)-\log P\left(X<D_{50}\right)}{\log \left(D_{84}\right)-\log \left(D_{50}\right)}
$$

where $P\left(D_{84}\right)$ and $P\left(D_{50}\right)$ are the proportions by weight smaller than the 84 th and 50 th percentiles, respectively.

The fractal dimension of weathering products from a number of catchments in southern Italy (Basilicata, Campania, and Calabria; fig. 6) was also calculated using this interpolation method (table 4). Catchments in Basilicata and Campania are underlain by Flysch mudstones and sandstones, carbonates, and red chert, whereas those in Calabria are underlain by gneiss and granite. The grain size properties at the outlets of 23 of these catchments were also measured using the Wolman clast-count method, so that weathering products and sediment at the point of export could be compared.

Results. Results are presented for samples collected at catchment outlets in Sicily, from trunk channels in three of those catchments, from regolith in southern Italy, and at the outlet points of catchments along extensional faults in southern Italy.

Samples at Catchment Outlets, Sicily (Table 2). Values for the slope of the linear regression $m$ are given in table 2, together with the fractal dimension $D_{\mathrm{f}}$. All the fractal dimensions based on sieving at catchment outlets are between 2 and 3 (fig. 4), with an average value of 2.61 from 10 localities with $R^{2}>0.90$. Estimates based on Wolman clast-count data give an average fractal dimension of 2.57 from 13 localities with $R^{2}>0.90$, demonstrating that the two methods are compatible. Truncating data points at the very coarsest and finest grain sizes improves the regression. For sieved data, the average fractal dimension is insignificantly higher at 2.65 based on 17 localities, whereas for the Wolman method $D_{\mathrm{f}}$ is lower at 2.49 from 17 localities, indicating that the Wolman method records relatively more of the coarse fraction of the grain size distribution and, in comparison, sieving records relatively more of the fine fraction, as expected.

Graphs of fractal dimensions calculated from sieved data versus Wolman clast-count data without fine or coarse truncation, from all localities, gives a symmetrical spread about the $1: 1$ line, with 
Table 3. Grain Size Characteristics of Bedload Sediment in the Main Trunk Channel of the Pagliara, Fiumedinisi, and Agro Catchments, Sicily, Obtained by Sieving

\begin{tabular}{|c|c|c|c|}
\hline Upstream distance in $\mathrm{km}$ (locality ID) & $D_{84}(\mathrm{~mm})$ & $D_{50}(\mathrm{~mm})$ & $D_{\mathrm{f}}$ \\
\hline \multicolumn{4}{|l|}{ Pagliara: } \\
\hline $11.568(39)$ & 215.9 & 35.1 & 2.71 \\
\hline $11.015(37)$ & 39.2 & 16.3 & 2.41 \\
\hline $10.617(42)$ & 15.8 & 2.0 & 2.75 \\
\hline $10.599(41)$ & 30.3 & 4.7 & 2.72 \\
\hline $9.398(36)$ & 102.8 & 23.9 & 2.64 \\
\hline $7.125(35)$ & 72.1 & 13.3 & 2.69 \\
\hline 6.137 (34) & 49.3 & 9.1 & 2.69 \\
\hline $6.084(3)$ & 119.0 & 31.6 & 2.61 \\
\hline $3.458(1)$ & 39.1 & 12.8 & 2.53 \\
\hline 2.082 (44) & 31.0 & 4.0 & 2.75 \\
\hline $.425(33)$ & 31.5 & 6.4 & 2.67 \\
\hline Average & 64.1 & 22.4 & 2.65 \\
\hline \multicolumn{4}{|l|}{ Fiumedinisi: } \\
\hline $11.300(25)$ & 110.5 & 27.3 & 2.63 \\
\hline $11.020(27)$ & 125.7 & 50.6 & 2.43 \\
\hline $10.816(21)$ & 46.5 & 16.6 & 2.50 \\
\hline $9.255(6)$ & 153.6 & 48.1 & 2.55 \\
\hline 9.185 (7) & 136.6 & 18.1 & 2.74 \\
\hline $6.730(28)$ & 30.1 & 9.5 & 2.55 \\
\hline $5.862(29)$ & 139.0 & 29.3 & 2.67 \\
\hline $3.579(10)$ & 137.1 & 43.8 & 2.55 \\
\hline $1.859(5)$ & 105.2 & 26.8 & 2.62 \\
\hline $1.100(30)$ & 54.3 & 13.9 & 2.62 \\
\hline Average & 76.3 & 34.1 & 2.59 \\
\hline \multicolumn{4}{|l|}{ Agro: } \\
\hline 14.269 (49) & 77.5 & 22.7 & 2.58 \\
\hline $12.165(62)$ & 35.1 & 5.5 & 2.72 \\
\hline $8.154(60)$ & 37.5 & 9.7 & 2.62 \\
\hline 6.309 (54) & 105.7 & 16.0 & 2.72 \\
\hline $6.178(53)$ & 26.5 & 3.0 & 2.76 \\
\hline $5.982(52)$ & 33.17 & 6.7 & 2.68 \\
\hline $4.365(51)$ & 46.34 & 6.5 & 2.74 \\
\hline $4.192(55)$ & 37.1 & 6.4 & 2.70 \\
\hline 2.687 (50) & 32.8 & 4.7 & 2.73 \\
\hline $.548(45)$ & 44.2 & 5.4 & 2.75 \\
\hline Average & 49.2 & 8.9 & 2.70 \\
\hline
\end{tabular}

up to $10 \%$ deviation (fig. $5 \mathrm{~A}$ ), whereas the truncated data with a free intercept indicate a preferred drift of up to $20 \%$ (fig. $5 B$ ). This asymmetry again suggests that sieved data representing the full grain size distribution may exhibit somewhat higher fractal dimensions than Wolman clast counts restricted to gravel. In general, however, the fractal dimensions calculated from the two methods are closely comparable.

Trunk Channels of Catchments, Sicily (Table 3). The average fractal dimension calculated by interpolation between the grain sizes of $D_{84}$ and $D_{50}$ obtained by sieving in the main channel of the Pagliara, Fiumedinisi, and Agro catchments ranges from 2.59 for the large $\left(50-\mathrm{km}^{2}\right)$ Fiumedinisi catchment $(n=10)$ to 2.65 for the small $\left(27-\mathrm{km}^{2}\right)$ Pagliara catchment $(n=11)$ and to 2.70 for the largest $\left(83-\mathrm{km}^{2}\right)$
Agro catchment $(n=10)$, suggesting that there is no clear dependency of fractal dimension on catchment area within the range investigated in this study (fig. 4). There are no significant downstream trends in the ratio $D_{84} / D_{50}$ or in the fractal dimension. All catchments have fractal dimensions that are indistinguishable from those calculated from sediment at the river outlets. Evidently, the geometric ratio $D_{84} / D_{50}$ from clast counts can reliably be used to estimate fractal dimensions without the need for labor-intensive sieving.

Regolith, Southern Italy (Table 4). Weathering products in catchments in Campania-Basilicata (17 localities) and Calabria (6 localities; fig. 6) have fractal dimensions that range from an average of $2.30(n=6)$ for the gneisses and granites of Calabria to $2.42(n=6)$ for the Flysch mudstones and 
A

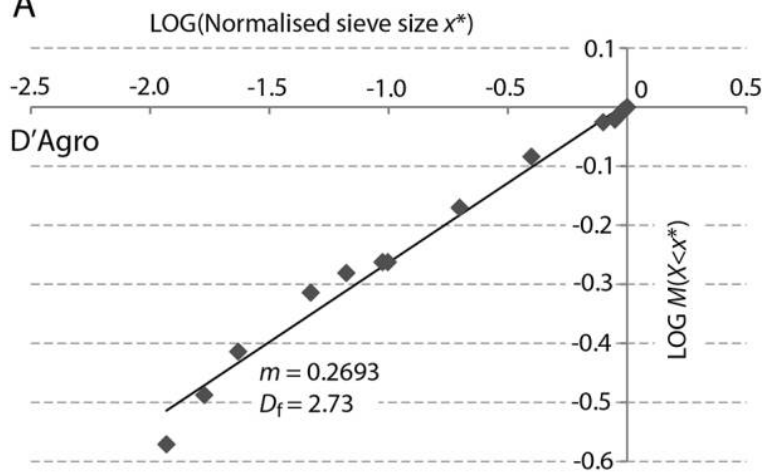

B

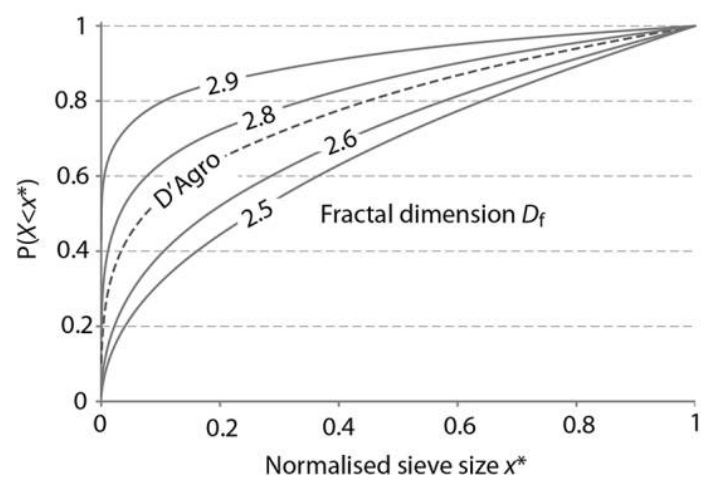

Figure 3. A, Log-log plot of the normalized grain size $x^{*}=x / x_{\max }$ versus the mass smaller than the sieve size with a straight line fit of gradient $m$. Data are for a sieved sample obtained at a locality at the mouth of the D'Agro catchment, eastern Sicily. $B$, Cumulative distribution function for grain size for a range of values of the fractal dimension. The cumulative distribution function that best fits the $\mathrm{D}^{\prime}$ Agro data is shown $\left(m=0.27, D_{\mathrm{f}}=2.73\right)$. There is a greater contribution from fine grain sizes with higher values of the fractal dimension.

sandstones of Campania-Basilicata and to 2.48 $(n=10)$ for the carbonates of Campania-Basilicata (fig. 7A). However, the fractal dimension for weathering products is highly variable for catchments underlain by Flysch mudstones and sandstones and gneisses/granites but is relatively uniform for catchments underlain by carbonates. This property has significance for the export of sediment from catchments of different bedrock lithology.

Catchment Outlets, Southern Italy. The estimated values of fractal dimension from weathering products can be compared with those for sediment at the outlets of catchments in the same region. Sediment at the outlets of 23 catchments along the Vallo di Diano and East Agri faults in Campania-Basilicata have an average fractal dimension of 2.42 by the interpolation method (fig. $7 B$ ). This value reflects the mixed bedrock lithologies and is very close to the average of the weathering products in the tectonically uplifting catchments, showing that weathering products are little modified during the process of sediment mobilization before export to adjacent basins. In addition, the variation in fractal dimension at catchment outlets is small compared with the variation in the regolith caused by lithologic controls. This suggests that although the average fractal dimension changes little from regolith to catchment outlet, the source materials undergo some homogenization. It is expected that large catchments are more effective at homogenization than small, but no relationship between fractal dimension and contributing drainage area is evident (fig. $7 B$ ).

In summary, the fractal dimension of weathering products and sediment at catchment outlets in southern Italy are identical and are a good indicator of the grain size mix of the sediment supply to sedimentary basins. Likewise, in Sicily the fractal dimensions of sediment sampled at a number of stations along the main trunk channels of three catchments are indistinguishable from those calculated from sediment at catchment outlets (fig. 4).

\section{Numerical Simulations Using a Variable Grain Size Distribution in the Supply}

We have shown that the fractal dimension of the grain size distribution of sediment stored in upland catchments as regolith and bedload of trunk channels lies within a range that is explainable by the dominant control of fragmentation but with variability caused by differences in bedrock lithology. Information on the grain size mix of the sediment supply to basins is critical for down-system prediction. Simulations are therefore carried out using a physical sediment transport model to test the sensitivity of stratigraphic architectures to variations in the grain size characteristics of the supply.

Although the fractal dimension has the advantage of describing the grain size distribution of sediment in one number, fractal distributions do not have meaningful values of mean and standard deviation since they are scale invariant. However, the fractal power law, represented by equation (1), has the same form as the Pareto distribution, which is described by a shape parameter $a$ representing the spread of the distribution and a scale parameter $k$ representing the minimum grain size (Schroeder 1991; Hastings and Sugihara 1993; Vidondo et al. 1997). The unknown parameters of the Pareto distribution can be evaluated by interpolation between specified grain size values. Here, interpolation is carried out using values of the 84th and 50th percentiles derived from the cumulative function dis- 

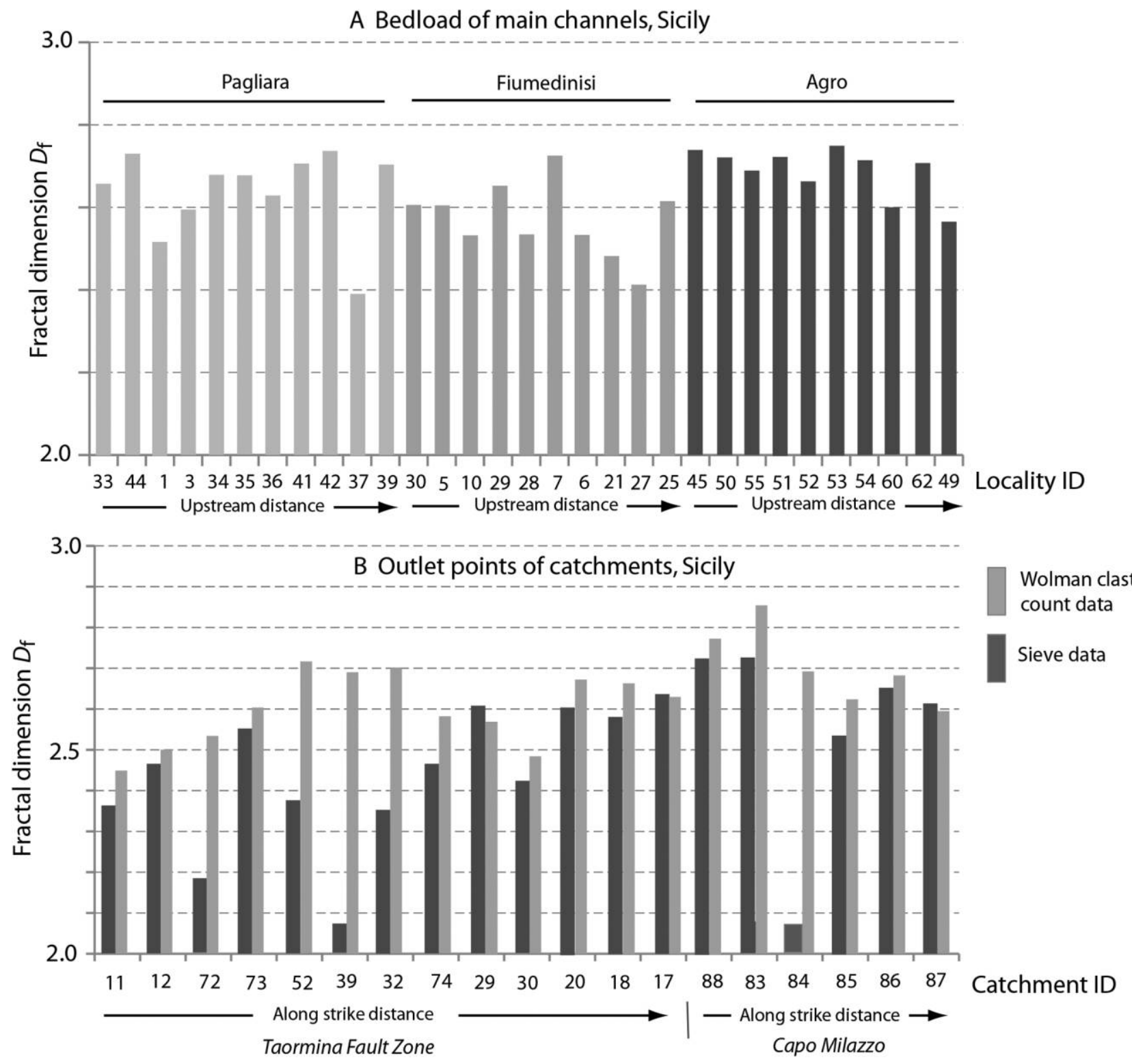

Figure 4. A, Histogram of fractal dimension for bedload samples in the main channels of the Pagliara, Fiumedinisi, and Agro catchments, Sicily. Localities are arranged according to distance upstream of the outlet. $B$, Fractal dimension from sediments at the outlet points of catchments etched into a region of active tectonic uplift in Sicily based on Wolman clast-count and sieve data. Localities are arranged on the basis of the along-strike distance along the basin-margin faults. A color version of this figure is available online.

tribution of grain size based on Wolman-type clast counts. If the proportion of a sample that has particles below a grain size $D_{\mathrm{b}}$ is denoted by $P_{\mathrm{b}}$ and the proportion of a sample that has particles below a grain size $D_{\mathrm{c}}$ is denoted by $P_{\mathrm{c}}$ the estimate of the shape parameter $a$ is

$$
a=\frac{\log \left(1-P_{\mathrm{b}}\right)-\log \left(1-P_{\mathrm{c}}\right)}{\log \left(D_{\mathrm{c}}\right)-\log \left(D_{\mathrm{b}}\right)}
$$

and the estimate of the scale parameter $k$ is given by

$$
k=\left\{\frac{P_{\mathrm{c}}-P_{\mathrm{b}}}{\left(1 / D_{\mathrm{b}}^{a}\right)-\left(1 / D_{\mathrm{c}}^{a}\right)}\right\}^{1 / a}
$$

Plots of fractal dimension $D_{\mathrm{f}}$ derived from sieved and clast-count data versus Pareto shape parameter $a$ derived from interpolation of $D_{84}$ and $D_{50}$ have a 

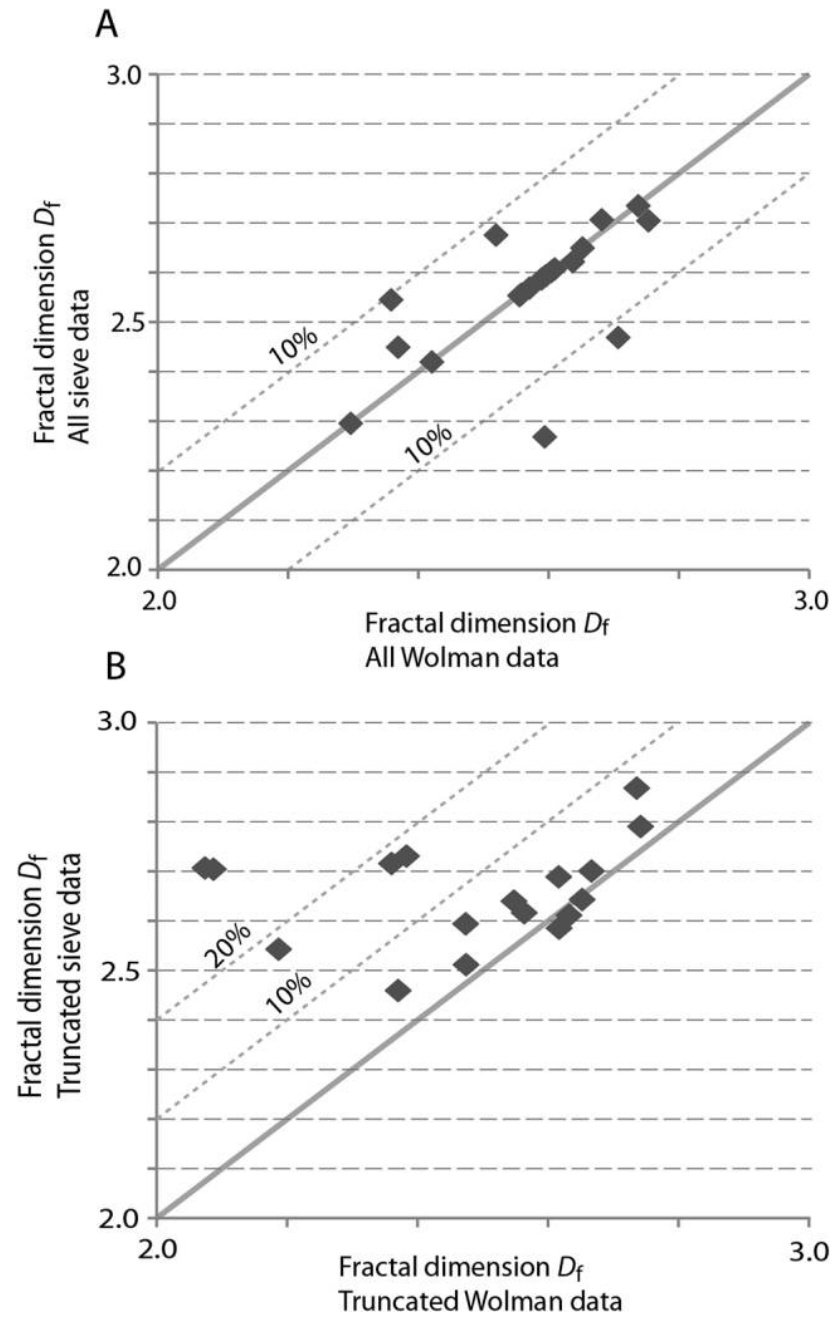

Figure 5. A, Plot of the fractal dimension derived from sieve data versus $D_{\mathrm{f}}$ derived from the Wolman clastcount method at the same localities at outlet points of catchments along the topographic range front, eastern Sicily. The plot includes all data without coarse or fine truncation of the log-log plots. The bulk of the data points fall with $10 \%$ of the $1: 1$ line. $B$, Plot of the fractal dimension from sieve data versus $D_{\mathrm{f}}$ derived from the Wolman clast-count method at the same localities at outlet points of catchments along the topographic range front. The plot shows values of $D_{\mathrm{f}}$ obtained after truncation of linear regressions in log-log plots at the very coarse and fine ends. Truncation leads to asymmetry in the data cloud, with $D_{\mathrm{f}}$ from sieving exceeding that from Wolman clast counting.

regression $D_{\mathrm{f}}=3-0.45 a$, from which it can be seen that $a \approx 2.22 \mathrm{~m}$.

The mean of the Pareto distribution $\mu_{\mathrm{P}}$ is given by

$$
\mu_{\mathrm{P}}=\frac{a k}{a-1}
$$

for $a>1$. This mean value for a Pareto distribution with shape parameter $a$ and scale parameter $k$ can be used to calibrate the input to a sediment dispersal model. For the sediment samples analyzed, $\mu_{\mathrm{P}}$ ranges between approximately 10 and $60 \mathrm{~mm}$.

The downstream trend in particle size is generally treated as exponential (Sternberg 1875; Pizzuto 1995; Rice 1999). The observed rate of downstream fining is commonly too rapid to be explained by abrasion and instead is interpreted as being due to size-selective deposition (Fedele and Paola 2007; Attal and Lave 2009). Duller et al. (2010) examined the sensitivity of downstream fining in gravels to changes in the controlling variables, such as the initial sediment discharge and the background tectonic subsidence, as well as to parameters relating to the grain size distribution of the sediment.

We initially disperse sediment down-system using a simple Sternberg-type exponential function of the form

$$
\mu\left(x^{*}\right)=\mu_{0} \exp \left(-C y^{*}\right),
$$

where $\mu_{0}$ is the mean grain size of the sediment supply, taken as the mean of clasts with a Pareto size distribution $\mu_{\mathrm{P}} ; \mu\left(x^{*}\right)$ is the mean grain size as a function of the normalized down-system distance $x^{*}=x / L ; L$ is the total depositional length of interest in the sediment routing system; $y^{*}\left(x^{*}\right)$ is the cumulative down-system sediment deposition in the normalized (mass balance) coordinate system; and $C$ is a coefficient that describes the rate of decrease in mean grain size in the down-system direction. If the initial mean grain size is $60 \mathrm{~mm}$ and the normalized cumulative down-system deposition is 0.5 (that is, half of the total sediment has been deposited), the mean grain size of the deposit ranges from 36 to $47 \mathrm{~mm}$ for values of $C$ between 1 and 0.5 , respectively. $C$ therefore reflects the fractionation of clasts from the surface flux, which depends on its variance of grain size. This in turn should be inversely dependent on the Pareto shape parameter of the sediment supply. $C$ is taken to be 0.75 in the simulations. The value of $\mu_{\mathrm{P}}$ is used as the mean of the sediment supply $\mu_{0}$ in equation (8), which becomes

$$
\mu\left(x^{*}\right)=\frac{a k}{a-1} \exp \left(-C y^{*}\right) .
$$

Equation (8) is a simplified version of that proposed by Fedele and Paola (2007) and applied by Duller et al. (2010) and Armitage et al. (2011), which includes terms for variance of the grain size distribution. The normalized grain size trend $\mu\left(x^{*}\right)$ is given by

$$
\mu\left(x^{*}\right)=\mu_{0}+\sigma_{0} \frac{C_{2}}{C_{1}}\left[\exp \left(-C_{1} y^{*}\right)-1\right]
$$


A) CAMPANIA AND BASILICATA

$15^{\circ} 30^{\prime} 0^{\prime \prime} \mathrm{E}$

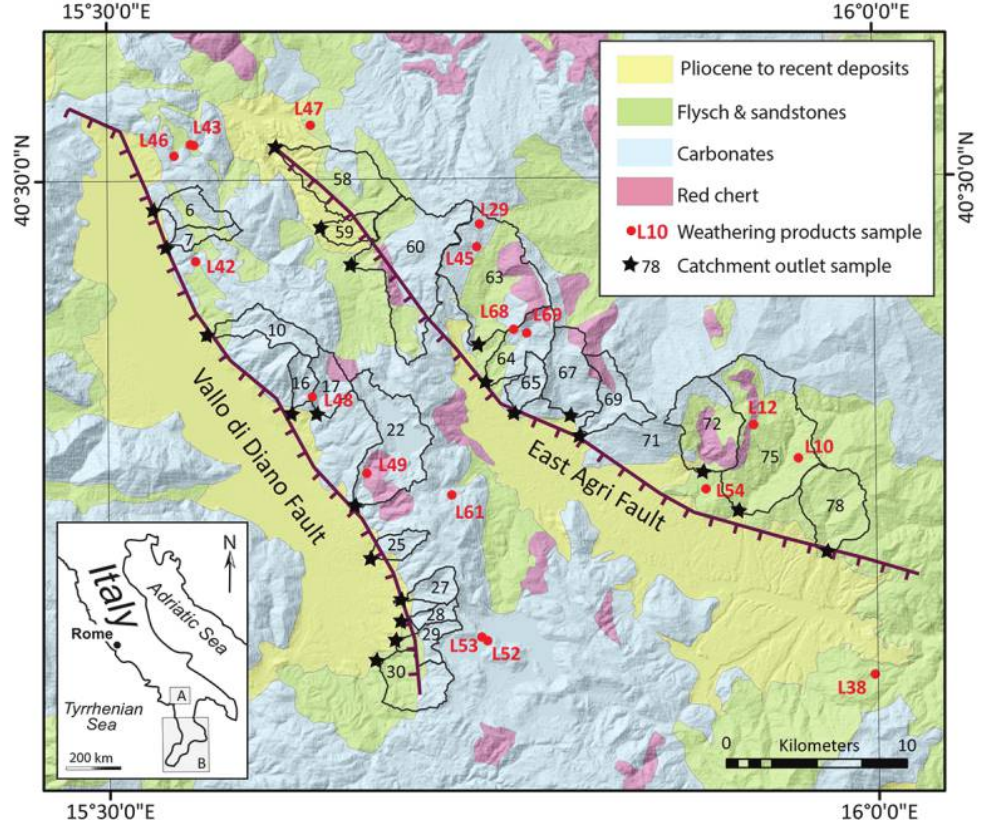

B) CALABRIA

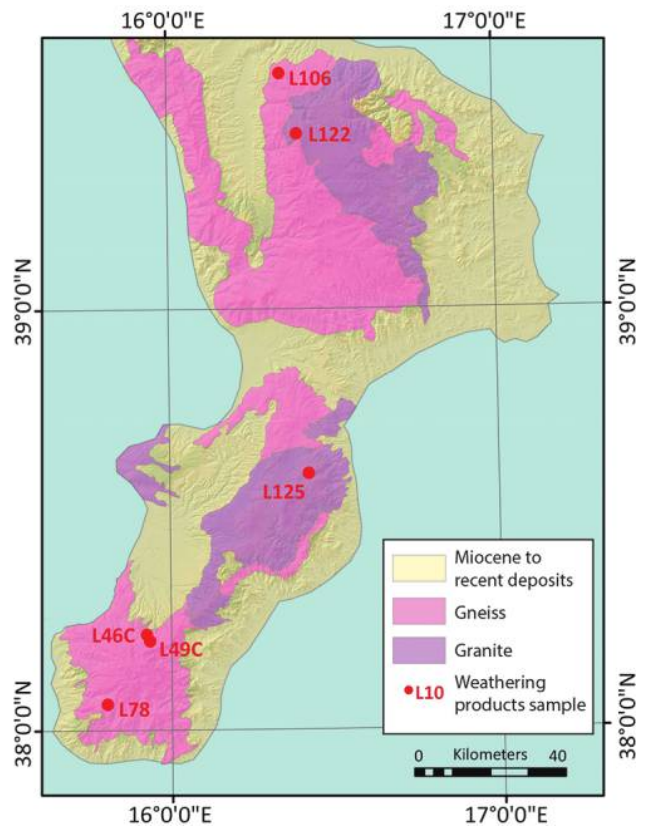

Figure 6. Simplified lithologic maps of the Campania-Basilicata $(A)$ and Calabria $(B)$ field areas, overlying a hillshaded digital elevation model image. Localities of field sampling of weathering products are shown in red, and sampling sites of sediments at the outlets of footwall catchments are marked with a black star.

where $\mu_{0}$ and $\sigma_{0}$ are the mean grain size and standard deviation in the sediment supply, respectively; $y^{*}\left(x^{*}\right)$ is the normalized cumulative downstream sediment deposition; $X^{*}$ is the normalized downsystem distance $(x / L)$; and the coefficients $C_{1}$ and $C_{2}$ describe the local variability related to the transfer of particulate material from the surface flow into the sedimentary deposit at a particular site and the regional variability arising from downstream change in the mean grain size in the whole system, respectively. Conceivably, there could be perfect selectivity of particles during selective deposition, in which case there would be zero variance at a particular site but strong downstream fining. On the other hand, selectivity of grain sizes during the extraction from the surface flow into the deposit may be weak, in which case the variance in the deposit may be high but the downstream fining small. The ratio of the two constants, $C_{1} / C_{2}$, termed the coefficient of variation $C_{\mathrm{v}}$, has a limited range of values and is approximately constant for a fluvial system. $C_{1}$ exists over a theoretical range of 0.55 to 0.95 (fig. 4 in Duller et al. 2010), with high values of $C_{1}$ promoting more rapid rates of downstream fining.

Equation (10) shows that the downstream fining of gravel is sensitive to the standard deviation in the sediment supply $\sigma_{0}$ (Paola and Seal 1995; Robinson and Slingerland 1998; Fedele and Paola
2007). More rapid rates of downstream fining occur at high values of $\sigma_{0} / \mu_{0}$, since a wider variation in clast sizes allows the largest clasts to be extracted more rapidly (fig. 5 in Duller et al. 2010). A plot of $\sigma_{0} / \mu_{0}$ (where $\sigma_{0}$ is the standard deviation in the sediment supply and $\mu_{0}$ is the mean grain size in the supply) using clast-count data from catchment outlets along the topographic range front in Sicily and Campania-Basilicata and from weathering products in Campania-Basilicata and Calabria versus fractal dimension and Pareto shape parameter is shown in figure 8 . As $D_{\mathrm{f}}$ increases and $a$ decreases, there is an increasing contribution to the distribution from small fragments, which is reflected in an increase in the value of $\sigma_{0} / \mu_{0}$. Most values of $\sigma_{0} / \mu_{0}$ fall in the range $0.6-1.7$, which corresponds to the range of $2<D_{\mathrm{f}}<3$ and $0<a<2.22$ found in the southern Italian and Sicilian data sets. This range of $\sigma_{0} / \mu_{0}$ is employed in the numerical simulations.

Simulations of the downstream fining of mean grain size are carried out with background subsidence approximated by an exponential function, analogous to an extensional halfgraben bounded by a border fault or to a flexural foreland basin (Allen and Allen 2013). The discharge of the sediment supply and the spatial distribution of tectonic subsidence are kept steady during model runs. 
Table 4. Grain Size Characteristics of Weathering Products (Regolith) from Catchments in Southern Italy Derived from the Wolman Clast-Count Method

\begin{tabular}{|c|c|c|c|c|c|}
\hline & Locality ID & $D_{84}(\mathrm{~mm})$ & $D_{50}(\mathrm{~mm})$ & $D_{84} / D_{50}$ & $D_{\mathrm{f}}$ \\
\hline \multicolumn{6}{|l|}{ Flysch and sandstones (Campania-Basilicata): } \\
\hline Gorglione Formation (sandstones) & 10 & 50 & 7 & 7.14 & 2.72 \\
\hline Flysch Galestrino (siltstones/very fine sandstones) & 12 & 50 & 15 & 3.33 & 2.55 \\
\hline Flysch di Albidona (fine sandstones) & 38 & 48 & 17 & 2.82 & 2.48 \\
\hline Miocene sandstones ( $M_{\text {; }}$ calcareous sandstones) & 54 & 28 & 14 & 2.00 & 2.22 \\
\hline Monte Sierio Formation (M33; mudstones/fine sandstones) & 46 & 45 & 25 & 1.80 & 2.08 \\
\hline Monte Sierio Formation & 47 & 45 & 21 & 2.14 & 2.29 \\
\hline \multicolumn{6}{|l|}{ Carbonates (Campania-Basilicata): } \\
\hline Sucrosic limestones (E1C1) & 42 & 66 & 26 & 2.54 & 2.42 \\
\hline Calcarenites (L1T6) & 43 & 80 & 30 & 2.67 & 2.45 \\
\hline Calcarenites (L1T6) & 45 & 59 & 24 & 2.46 & 2.39 \\
\hline Dolomites (Ts) & 48 & 65 & 21 & 3.10 & 2.52 \\
\hline Calcarenites (CsCi) & 52 & 45 & 14 & 3.21 & 2.54 \\
\hline Calcarenites (Gs) & 53 & 20 & 50 & 2.50 & 2.41 \\
\hline Carbonate conglomerates (CsT6) & 61 & 92 & 27 & 3.41 & 2.56 \\
\hline Cherty limestones (TsT4) & 68 & 65 & 26 & 2.50 & 2.41 \\
\hline Cherty limestones (TsT4) & 69 & 72 & 28 & 2.57 & 2.43 \\
\hline Cherty limestones (TsT4t) & 29 & 53 & 21 & 2.52 & 2.41 \\
\hline Red chert (GsTs) & 49 & 51 & 22 & 2.32 & 2.35 \\
\hline \multicolumn{6}{|l|}{ Granites and gneisses (Calabria): } \\
\hline Gneiss & 46 & 58 & 25 & 2.32 & 2.36 \\
\hline Gneiss & 49 & 71 & 35 & 2.03 & 2.23 \\
\hline Gneiss & 78 & 51 & 29 & 1.76 & 2.04 \\
\hline Gneiss & 125 & 60 & 32 & 1.88 & 2.14 \\
\hline Granite & 106 & 66 & 29 & 2.28 & 2.34 \\
\hline Granite & 122 & 43 & 15 & 2.87 & 2.49 \\
\hline
\end{tabular}

Note. The fractal dimension is obtained by interpolation of $D_{84}$ and $D_{50}$. Lithologic codes refer to Italian geologic maps.

In the sediment transport model, change in elevation of the deposited sediment is assumed to be a function of the subsidence and the divergence of sediment across the surface, following the Exner continuity equation for mass:

$$
\partial z / \partial t=U-\partial q_{\mathrm{s}} / \partial x,
$$

where $z$ is elevation, $U$ is the subsidence field taken to be an exponential profile with a maximum of $5 \mathrm{~mm} \mathrm{yr}^{-1}$, and $q_{\mathrm{s}}$ is the sediment flux.

To capture the first-order processes of sediment transport, we follow Smith and Bretherton (1972) and assume that sediment flux, $q_{\mathrm{s}}$, is a function of slope, $\partial z / \partial x$, and surface water flux, $q_{\mathrm{w}}$ :

$$
q_{\mathrm{s}}=-\kappa \frac{\partial z}{\partial x}-c q_{\mathrm{w}}^{n} \frac{\partial z}{\partial x}
$$

where $\kappa=0.01 \mathrm{~m}^{2} \mathrm{yr}^{-1}$ is a linear diffusion coefficient that captures gross-scale hill-slope processes, $c=1 \times 10^{-5} \mathrm{~m}^{-2} \mathrm{yr}^{-1}$ is the water transport coefficient, and $n=2$, following Simpson and Schlunegger (2003). Change in these parameters will affect how the system responds to changes in water flux and subsidence (Armitage et al. 2011, 2013). However, as we are interested in exploring how source grain size distribution affects the dispersal of sediment down-system, these parameters are fixed. Finally, the water flux is assumed to be given by the precipitation rate, $\alpha$, multiplied by the down-system length plus the water flux from the catchment of length $l_{\mathrm{c}}: q_{\mathrm{w}}=\alpha \mathrm{x}+\alpha 1_{\mathrm{c}}$. Sediment flux is then solved for a depositional domain that is $10 \mathrm{~km}$ long. The boundary conditions are of fixed elevation at the downstream limit of the system at $10 \mathrm{~km}$, and at the head of the system there is a constant supply of sediment of $1 \mathrm{~m}^{2} \mathrm{yr}^{-1}$ required to fill the basin.

Two sets of simulations are carried out:

1. Set A: A simple exponential decline in mean grain size is combined with the physical sediment transport model with steplike (A1) and gradual (A2) changes in the starting mean grain size $\mu_{\mathrm{P}}=\mu_{0}$ (figs. 9, 10).

2. Set B: Sediment deposition is governed by the self-similar solution of equation (10) combined with the physical sediment transport model with steplike (B1) and gradual (B2) changes in the ratio of the standard deviation to the mean grain size in the sediment supply $\sigma_{0} / \mu_{0}$ (figs. 11,12 ). $C_{\mathrm{v}}$ is held constant at 1.2 in the simulations, and $\sigma_{0} / \mu_{0}$ values are derived from field clast-count data.

In the case of the simple exponential model, the Pareto mean grain size in the sediment supply is held constant at $35 \mathrm{~mm}$ before a step or gradual change at 2.5-m.yr. model time. The step change involves a 


\section{A Weathering products, Campania-Basilicata and Calabria}

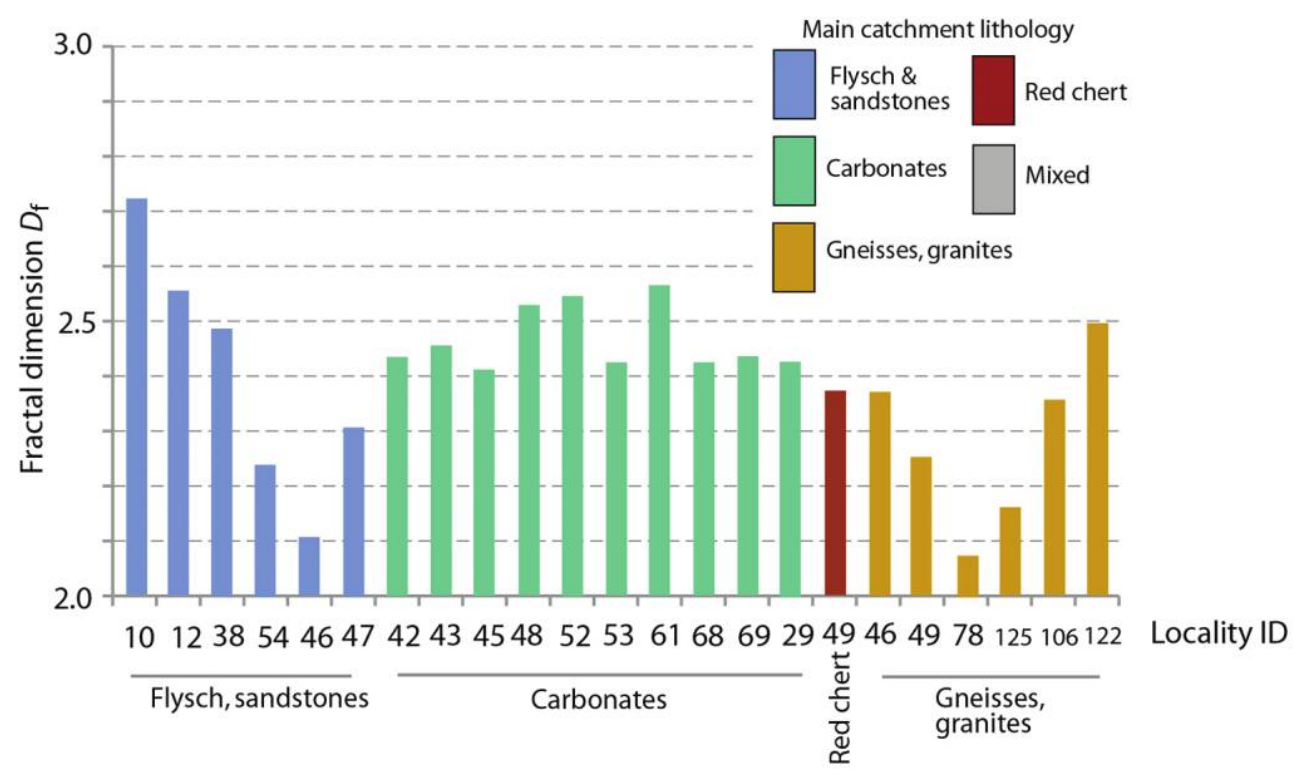

B Sediment at catchment outlets, Campania-Basilicata

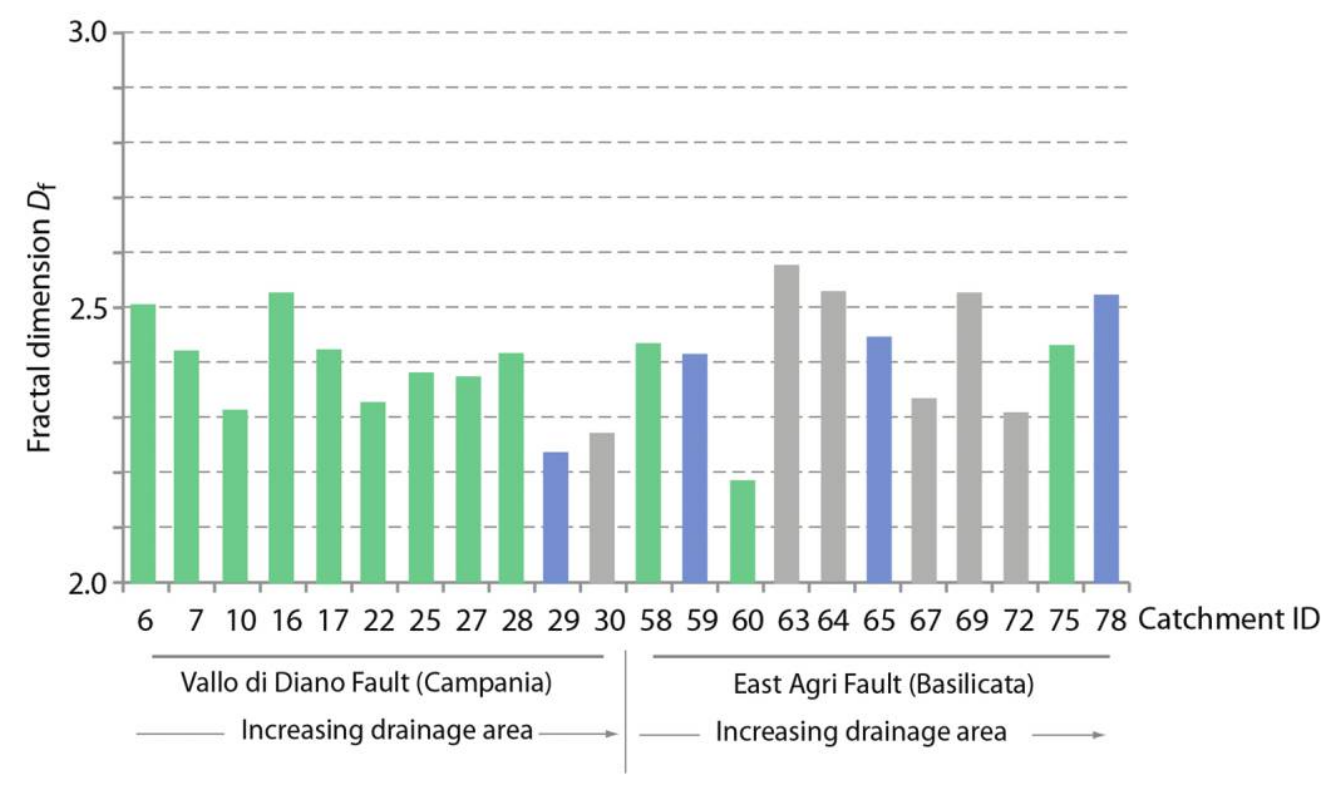

Figure 7. A, Histogram of the fractal dimension of weathering products in catchments in Campania-Basilicata and Calabria, southern Italy, with main catchment lithology. B, Histogram of the fractal dimension of sediments at the outlets of catchments in Campania-Basilicata along the Vallo di Diano and East Agri faults. Localities are arranged according to the size of the contributing drainage area.

doubling or halving of the Pareto mean followed by $2.5 \mathrm{~m}$.yr. of relaxation. In the case of a gradual change, the Pareto mean increases or decreases to values of 60 and $10 \mathrm{~mm}$ after 5-m.yr. model time. In the simulations using the self-similar solution of Fedele and Paola (2007), the value of $\sigma_{0} / \mu_{0}$ is set at 1.0 for the first $2.5 \mathrm{~m}$.yr., then increases to 1.5 or decreases to 0.5 in step or gradual changes. It is emphasized that the patterns of grain size in basin stratigraphy shown in the simulations are entirely driven by variations in the statistical properties of the grain size mix of the sediment supply.

Simulations using the simple exponential model show marked shifts in grain size at the time of the step change. A steplike increase in the mean size of the sediment supply causes an abrupt upward coars- 


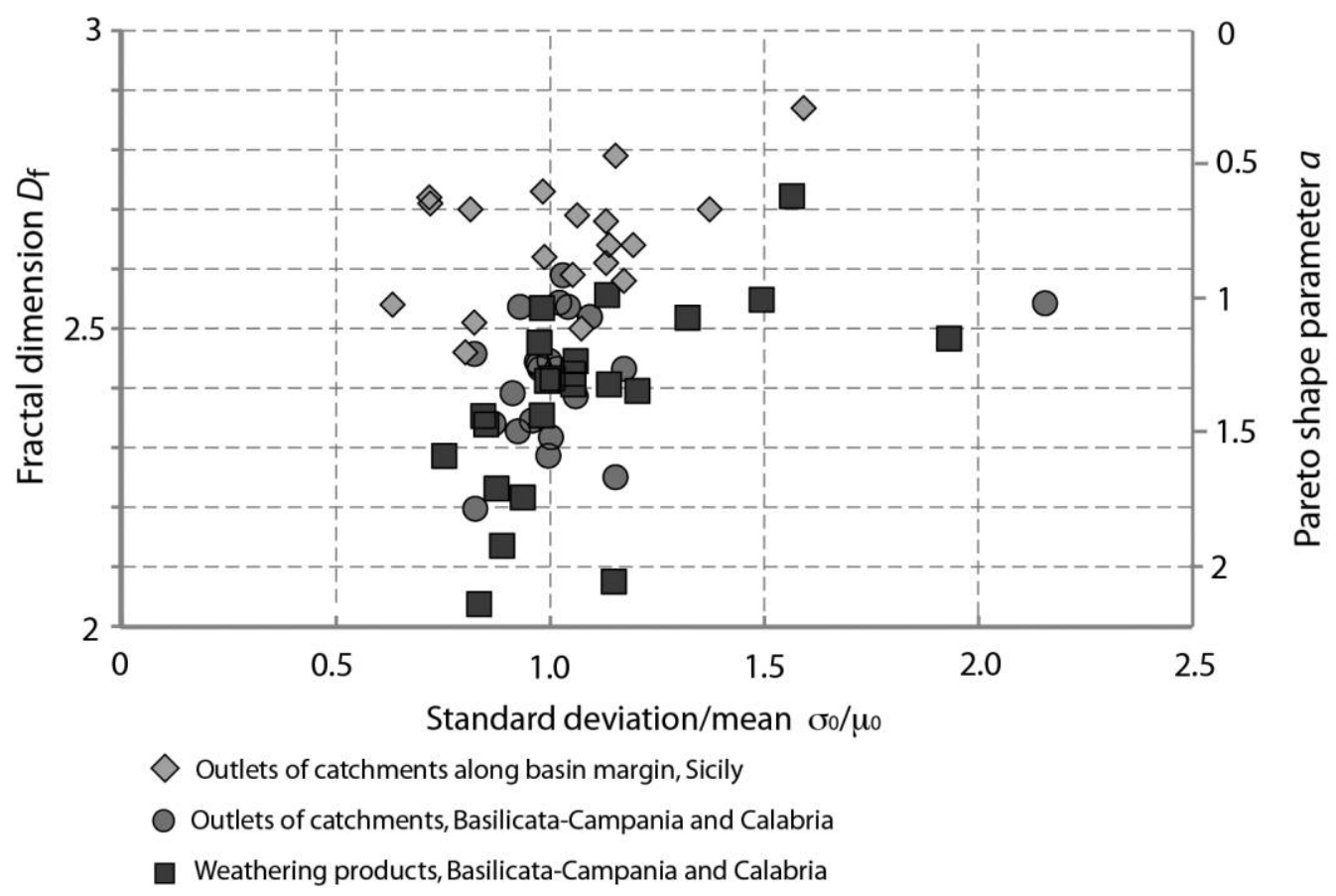

Figure 8. Plot of fractal dimension $D_{\mathrm{f}}$ and Pareto shape parameter $a$ versus the ratio $\sigma_{0} / \mu_{0}$, for a range of sediments and regolith in the erosional engine. There are considerable uncertainties in associating fractal dimensions to particular values of $\sigma_{0} / \mu_{0}$. The ratio $\sigma_{0} / \mu_{0}$ is, however, centered on a value of about 1 , and most values fall within the range 0.6-1.7. This range is incorporated into the simulations using a physical sediment transport model. A color version of this figure is available online.

ening and the down-system extension of the gravel front followed by gradual retrogradation, producing a tongue or sheet of coarse gravel. A steplike decrease in mean grain size of the supply causes an abrupt upward fining and retraction of the gravel front. A gradual increase in the mean size of the supply causes an upward coarsening, but the trend is relatively slow and leads to long-term progradation. Likewise, the gradual reduction in the mean size of the supply results in a basin-wide fining in stratigraphy and long-term retrogradation.

Sedimentary architectures generated in simulations using the self-similar solution are consistent with those using the simple exponential model. A steplike increase in the ratio $\sigma_{0} / \mu_{0}$ results in a pronounced gravel tongue, whereas the steplike decrease produces a surface marked by strong but short-lived retrogradation. A gradual increase in the ratio $\sigma_{0} / \mu_{0}$ causes an increase in progradation, resulting in a long-term trend of upward coarsening. A gradual decrease causes long-term retrogradation and slow upward fining.

Simulations reproduce features that are thought to be diagnostic of the relative sea level changes invoked in sequence stratigraphy, such as the abrupt upward fining and retrogradation associated with flooding surfaces and backstepping shoreline trajectories generated by relative sea level rise and the coarse-grained rapid regressions and prograding shoreline trajectories generated by relative sea level fall. These features were generated by variations in the grain size characteristics of the supply, with no changes taking place in base level, sediment flux, or tectonic subsidence.

\section{Discussion and Conclusions}

In present-day geomorphic settings, a range of factors can be identified that affect the breakdown of rock to produce regolith and sediment. The resulting grain size distribution is commonly fractal, representing the fragmentation process. In geologic settings, preserved stratigraphy represents the depositional record of ancient sediment routing systems, but the upland catchments acting as erosional engines have vanished by net erosion. Consequently, the precise contribution of the factors affecting the grain size characteristics of the sediment supply to basins is unknown and essentially unknowable. The broad characteristics of the grain size distribution of the sediment supply can, however, be approximated 

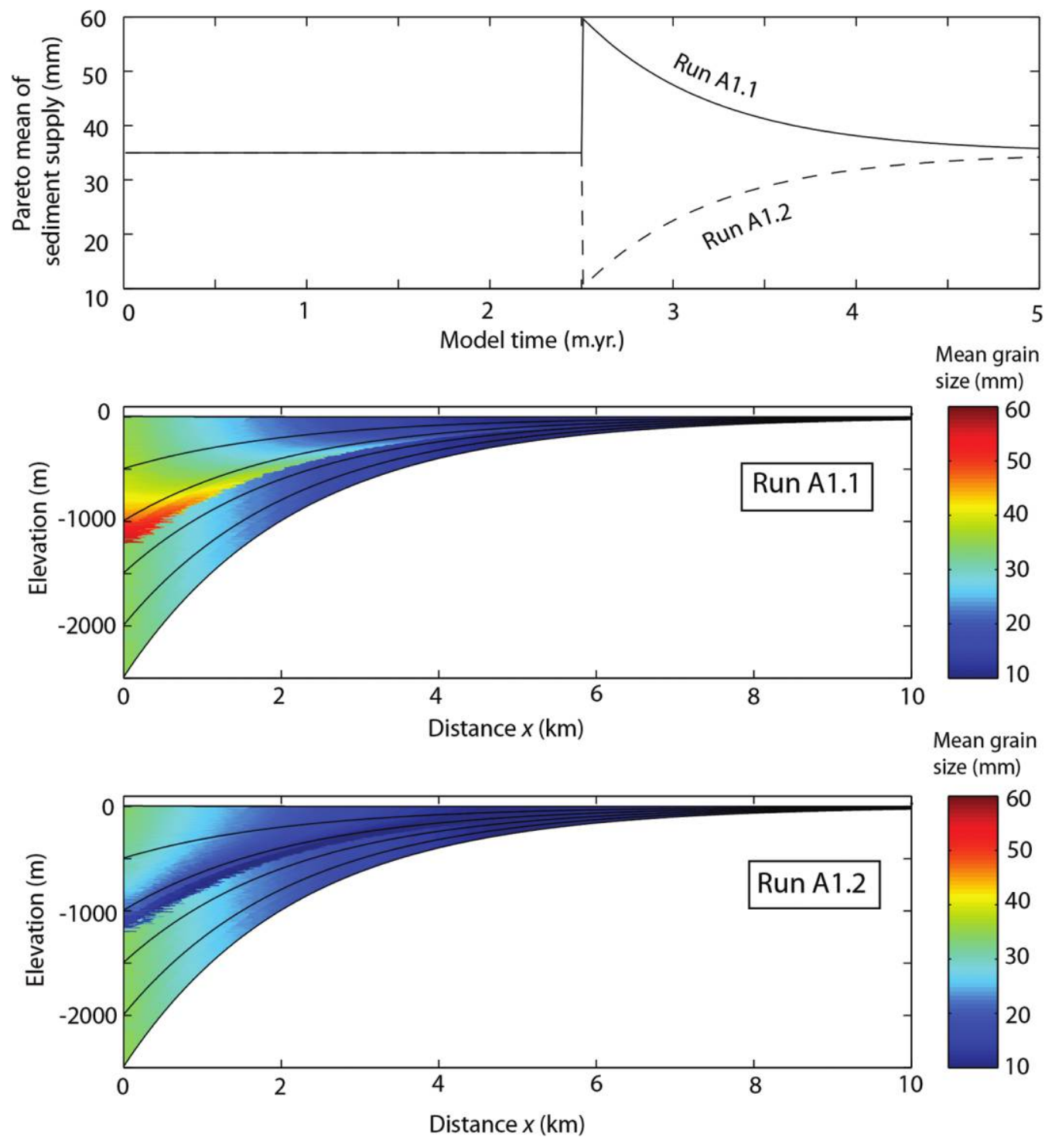

Figure 9. Simulation of grain size variation over a 5-m.yr. time period in a halfgraben or flexural-type basin with a maximum tectonic subsidence of $5 \mathrm{~mm} \mathrm{yr}^{-1}$, using a Sternberg-type exponential decline in mean grain size. Two scenarios are modeled involving a step-change increase (run A1.1) and step-change decrease (run A1.2) in the mean grain size of the sediment supply $\left(\mu_{0}\right)$, which has a distribution following the Pareto model. Step change takes place at 2.5 m.yr., followed by relaxation $(A) . B$ and $C$ show cross sections of the basin, with stratigraphy color coded for mean grain size $\mu(x)$. B shows the effects of a step-change increase in $\mu_{0}$ from 35 to $60 \mathrm{~mm}$, which causes an abrupt upward coarsening and an advance of the gravel front, followed by retrogradation. $C$ shows the effects of a step-change reduction in $\mu_{0}$ from 35 to $10 \mathrm{~mm}$, which causes an abrupt upward fining in grain size and upstream retraction of the gravel front, followed by gradual progradation.

by a single parameter, the fractal dimension, which describes the relative contribution of fine and coarse grain sizes to the grain size mix. We find that the fractal dimension of weathering products and bedload sediment in the trunk channels of upland catchments, including sediment at their outlet points, is within a relatively narrow range of 2.3-2.7. Grain size analysis of samples from catchments in south- ern Italy indicates that variations in bedrock lithology influence the estimates of fractal dimension but that such differences are partly homogenized during transport from regolith to the catchment outlet points. Future studies should examine this homogenization process more closely by investigating a broader range of catchment sizes, bedrock lithologies, and climatic variables. 


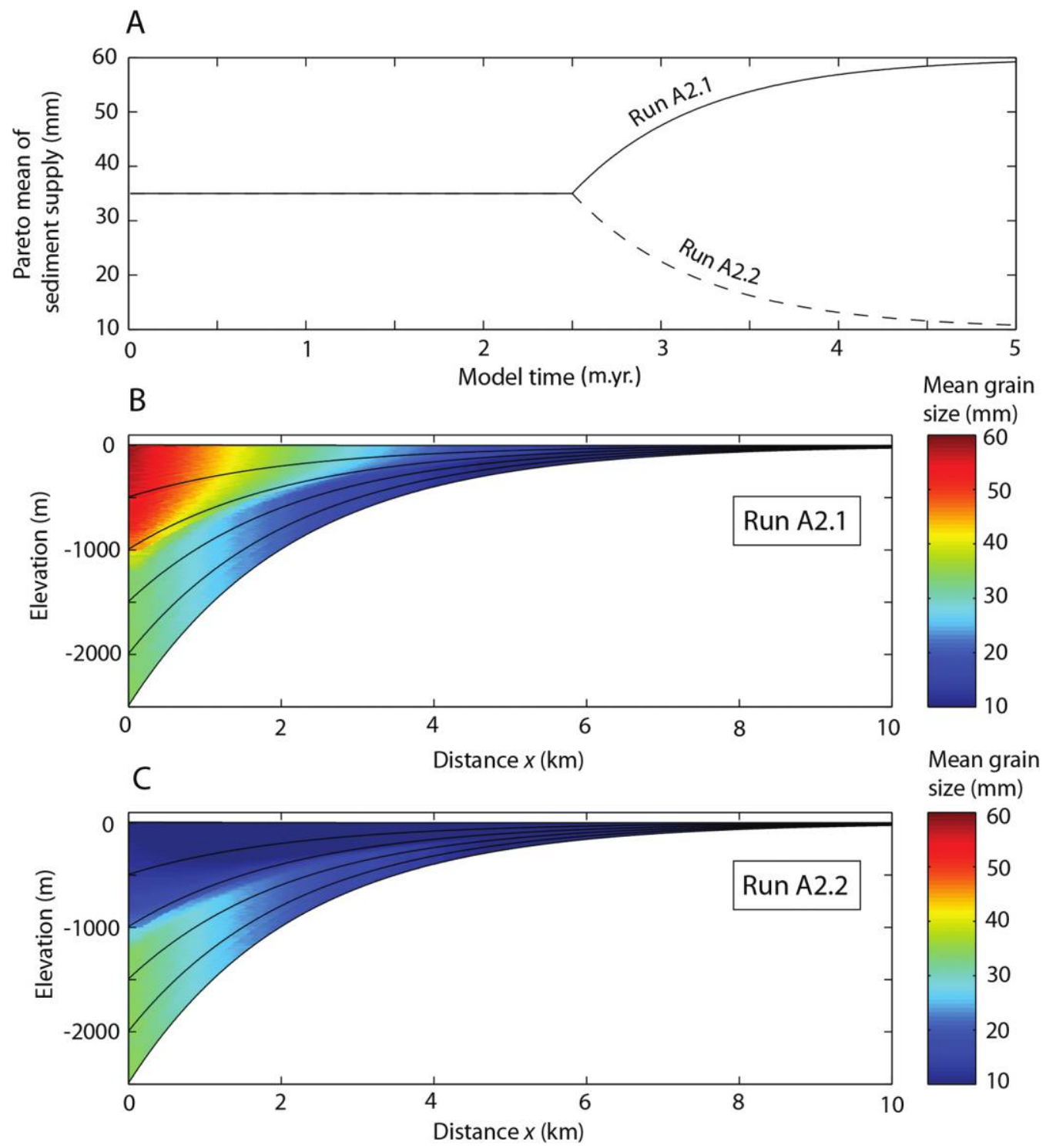

Figure 10. Simulation of grain size variation in a halfgraben or flexural-type basin with a maximum tectonic subsidence of $5 \mathrm{~mm} \mathrm{yr}^{-1}$ over a 5-m.yr. time period, using a Sternberg-type exponential decline in mean grain size. Two scenarios are modeled involving a gradual increase (run A2.1) and a gradual decrease (run A2.2) in the mean grain size of the sediment supply $\left(\mu_{0}\right)$, which has a distribution following the Pareto model $(A)$. $B$ and $C$ show cross sections of the basin, with stratigraphy color coded for mean grain size $\mu(x) . B$ shows the effects of a gradual increase in $\mu_{0}$ from 35 to $60 \mathrm{~mm}$, which causes an upward coarsening and prolonged progradation leading to a down-system extension of the gravel front. $C$ shows the effects of a gradual reduction in $\mu_{0}$ from 35 to $10 \mathrm{~mm}$, which causes an abrupt upward fining in grain size and upstream retraction of the gravel front.

Fractal dimensions obtained from sieving are marginally but systematically higher than those derived from the measurement of clasts of gravel grade using the Wolman method. Sieving of field samples provides the most accurate measure of the full grain size distribution but is laborious. However, Wolman clast measurement allows the calculation of the ratio of the 84th and 50th percentiles of gravel-grade sediment: these are close to the values obtained from sieving. Consequently, the Wolman method of clast size analysis provides a reliable indicator of the entire grain size spectrum.

Fractal distributions are scale invariant and do not have meaningful means and variances that might serve as input for numerical simulations of the downsystem dispersal of sediment. However, the Pareto distribution is uniquely characteristic of fractals. The unknown parameters of the Pareto distribution can 
A

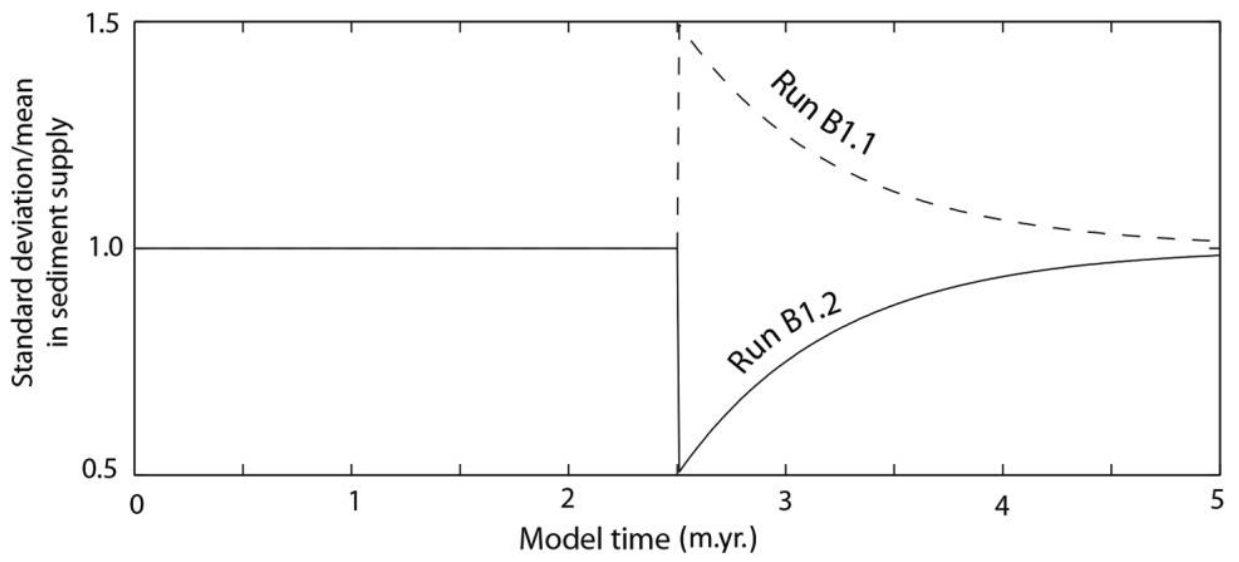

B

Mean grain

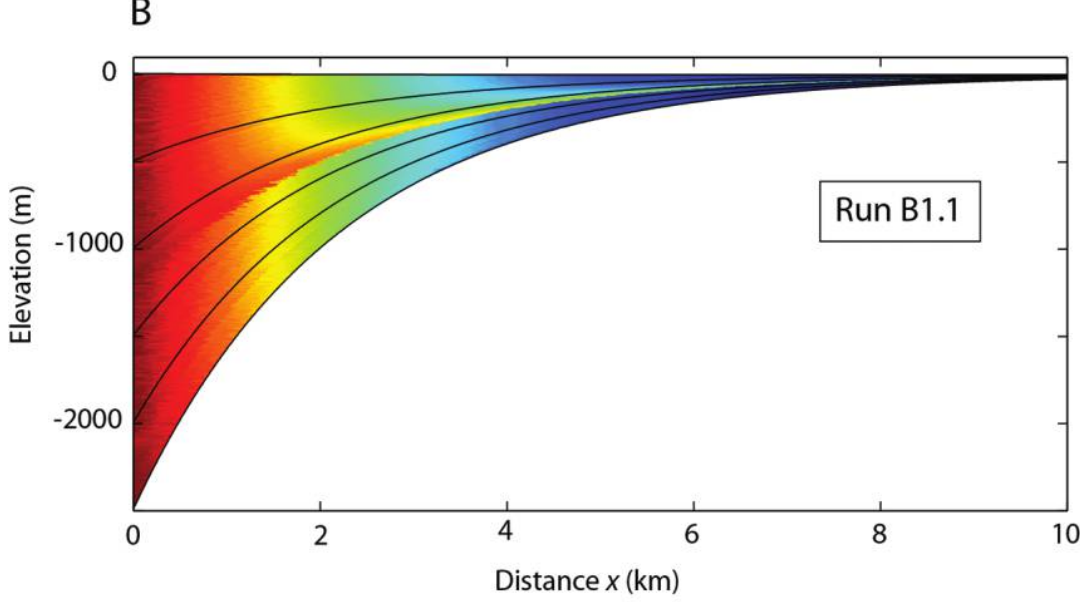

size $(\mathrm{mm})$

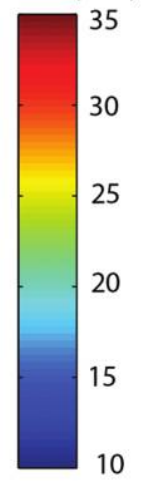

C

Mean grain

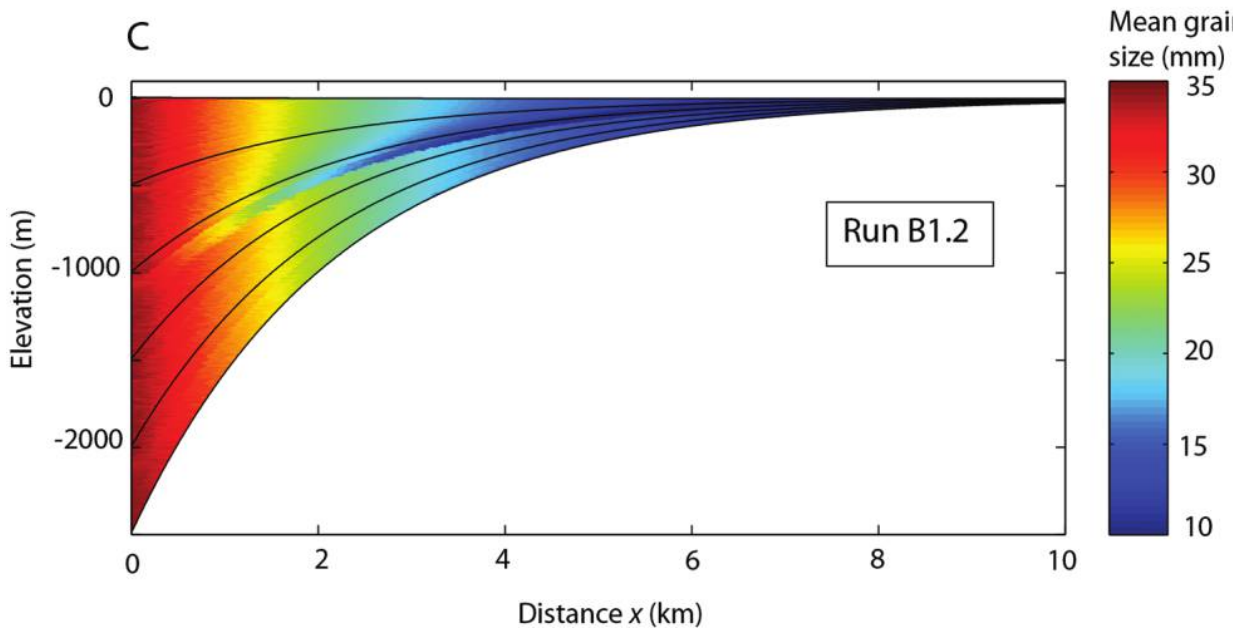

Figure 11. Simulation of grain size variation in a halfgraben or flexural-type basin with a maximum tectonic subsidence of $5 \mathrm{~mm} \mathrm{yr}{ }^{-1}$ over a 5-m.yr. time period, using the self-similar solution of Fedele and Paola (2007). Two scenarios are modeled involving a step-change increase (run B1.1) and a step-change decrease (run B1.2) in the ratio $\sigma_{0} / \mu_{0}$ at $2.5 \mathrm{~m}$.yr., followed by relaxation $(A) . B$ and $C$ show cross sections of the basin, with stratigraphy color coded for mean grain size $\mu(x)$. B shows the effects of a step-change increase in $\sigma_{0} / \mu_{0}$ from 1 to 1.5 , which causes an abrupt upward coarsening in grain size and a downstream extension of the gravel front. $C$ shows the effects of a step-change reduction in $\sigma_{0} / \mu_{0}$ from 1.0 to 0.5 , which causes an abrupt upward fining in grain size and a retreat of the gravel front, followed by slow progradation. 
A

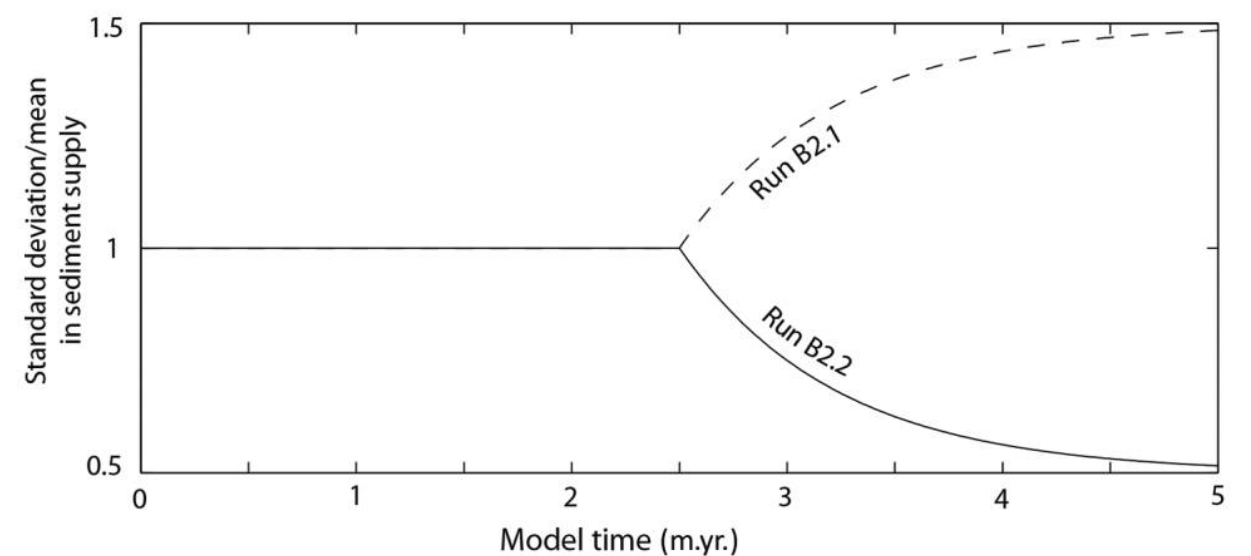

B

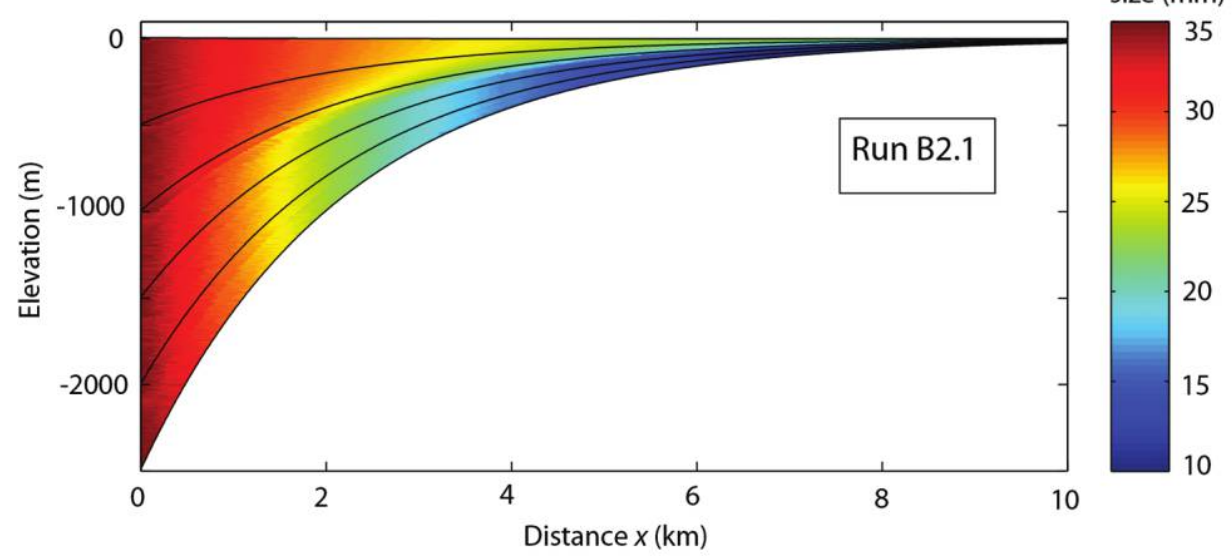

C

Mean grain

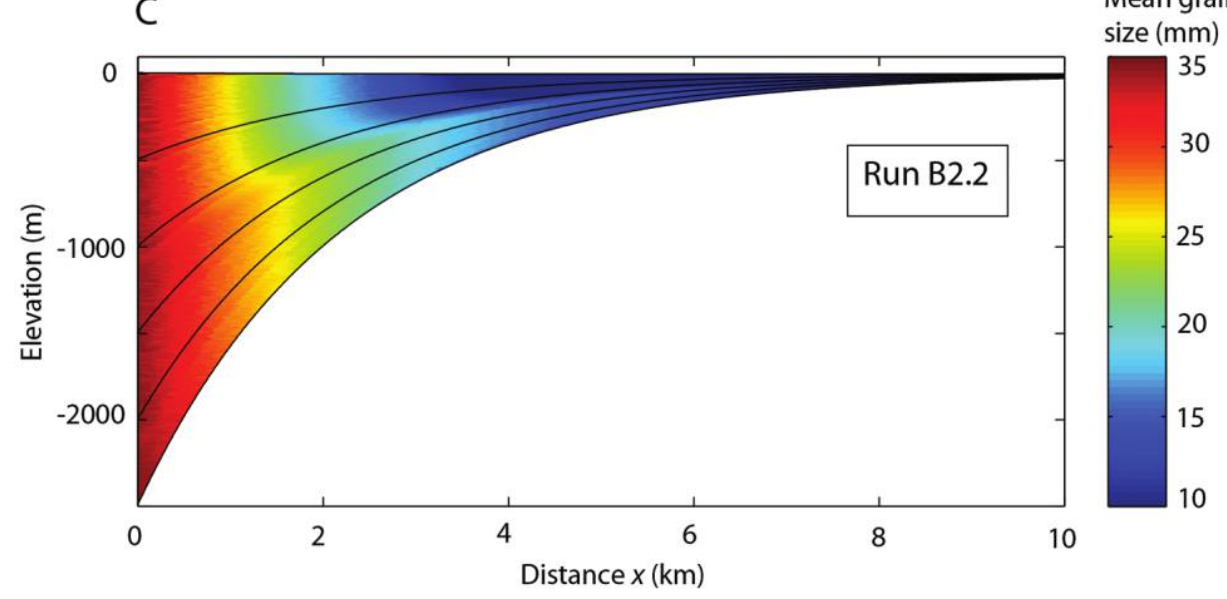

Figure 12. Simulation of grain size variation in a halfgraben or flexural-type basin with a maximum tectonic subsidence of $5 \mathrm{~mm} \mathrm{yr}^{-1}$ over a 5-m.yr. time period, using the self-similar solution of Fedele and Paola (2007). Two scenarios are modeled involving a gradual increase (run B2.1) and a gradual decrease (run B2.2) in the ratio $\sigma_{0} / \mu_{0}$ at $2.5 \mathrm{~m}$.yr. $(A) . B$ and $C$ show cross sections of the basin, with stratigraphy color coded for mean grain size $\mu(X)$. $B$ shows the effects of a gradual increase in $\sigma_{0} / \mu_{0}$, which causes an upward coarsening in grain size and progressive downsystem extension of the gravel front. $C$ shows the effects of a gradual reduction in $\sigma_{0} / \mu_{0}$, which causes a slight upward fining of mean grain size and minor retrogradation. 
be calculated by interpolation from values of the 84th and 50th percentiles, from which a mean can be estimated. This Pareto mean is used to characterize the sediment supply in numerical simulations, and the shape parameter of the Pareto distribution, which describes the spread of the grain size distribution, is directly related to the fractal dimension.

The first set of simulations uses a Sternberg-type exponential decline in mean grain size with distance, using an initial grain size in the sediment supply ranging between 10 and $60 \mathrm{~mm}$, corresponding to values of the Pareto shape parameter of 1.1-2.2 and values of the fractal dimension of 2-2.5. The second set of simulations uses the self-similar solution of Fedele and Paola (2007), with a $\sigma_{0} / \mu_{0}$ ratio of $0.5-$ 1.5. This is close to the range found in the field data sets from southern Italy and Sicily of $0.6-1.7$, corresponding to a range of fractal dimension of 2-3 and Pareto shape parameter of $0-2.2$. These ranges of values are applicable to the relatively small, steep, tectonically active catchments studied, but future research should examine the statistical properties of the sediment supply from as wide a range of lithologic, tectonic, topographic, and climatic settings as possible. By making steplike and gradual changes in the grain size mix of the sediment supply, stratigraphic trends are generated that conventionally would be interpreted as being due to base-level change or sediment flux variations. Stratigraphic grain size trends and architectures are therefore highly nonunique in terms of their forcing mechanisms.

A

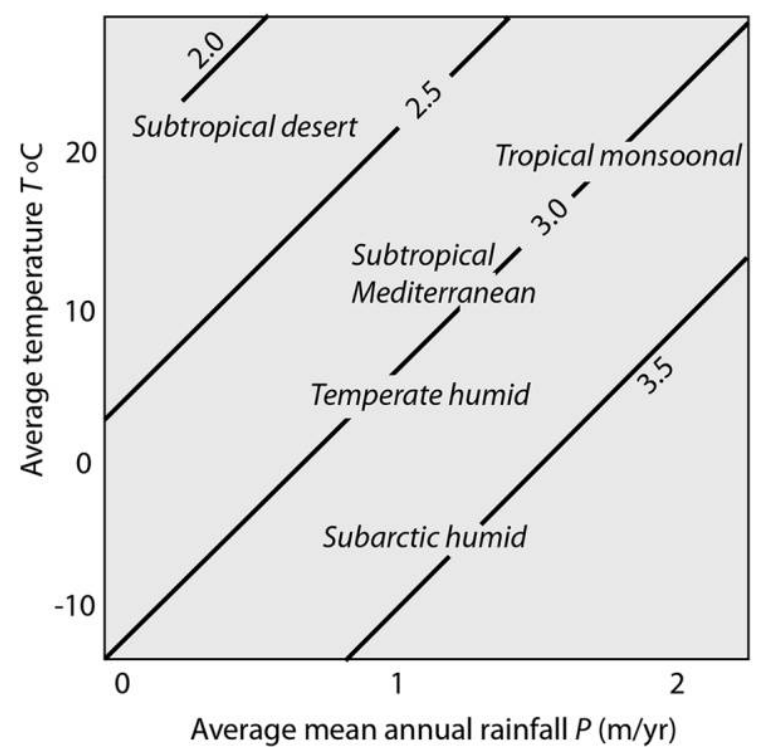

Fractal models of various types of aggregates and soils require the physical properties of the original material and the energy used in fragmenting this material to be known (Perfect 1997). There is therefore a potentially very wide range of factors that may be important, such as the mineralogy, crystal or grain size, porosity, presence of water (especially in clay-rich rocks and those with high pore-fluid pressure), and foliation (especially in slates, phyllites, and schists) of rocks and soils acting as original materials and the temperature changes (Smalley et al. 2005), wetting and drying (Smith et al. 2002), salt growth (Pye 1995), frost cracking (Wright et al. 1998), and transport processes - including rainsplash, biological disturbance, rockfalls, landslides and debris flows, wind, glaciers, and rivers (Smalley et al. 2006) - acting as energy sources for fragmentation. Such physical properties and energy sources are determined by the bedrock geology and regolith- and soil-forming processes in variable climatic and topographic settings. Yet there is at present a scarcity of systematic experimental and field observations on the fragmentation of natural materials comprising rocks and soils keyed to a range of topographic and climatic settings. Prolonged action and intense rates of disintegration processes, such as frost cracking, are expected to lead to relatively higher amounts of fine fragments, increasing the fractal dimension. Fracture density, structural fabric, and crystal/particle size affect the size distribution of fragments. These factors depend on the wide range of lithologic

B

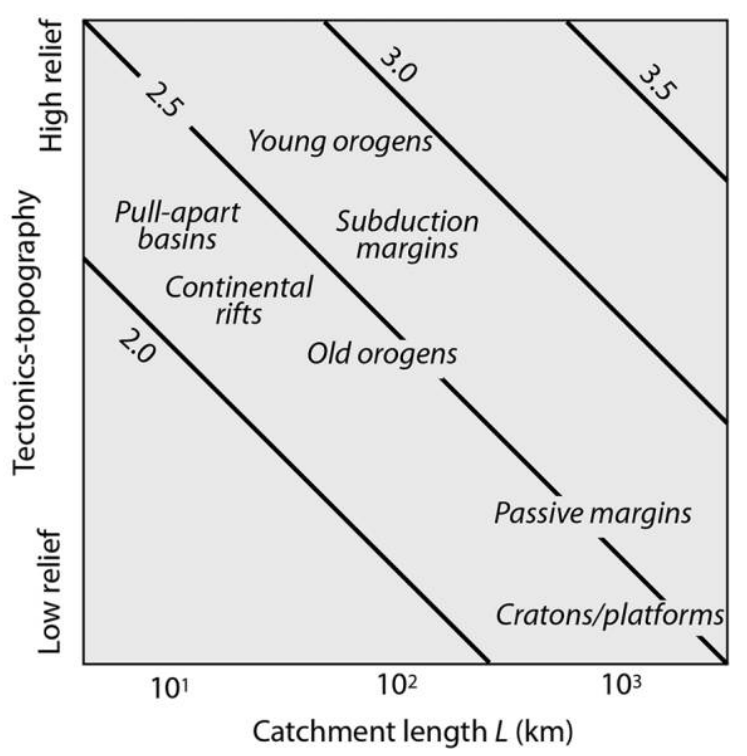

Figure 13. Speculative mapping of fractal dimension of regolith onto graphs of climatic parameters $(A)$ and geomorphic parameters $(B)$. 


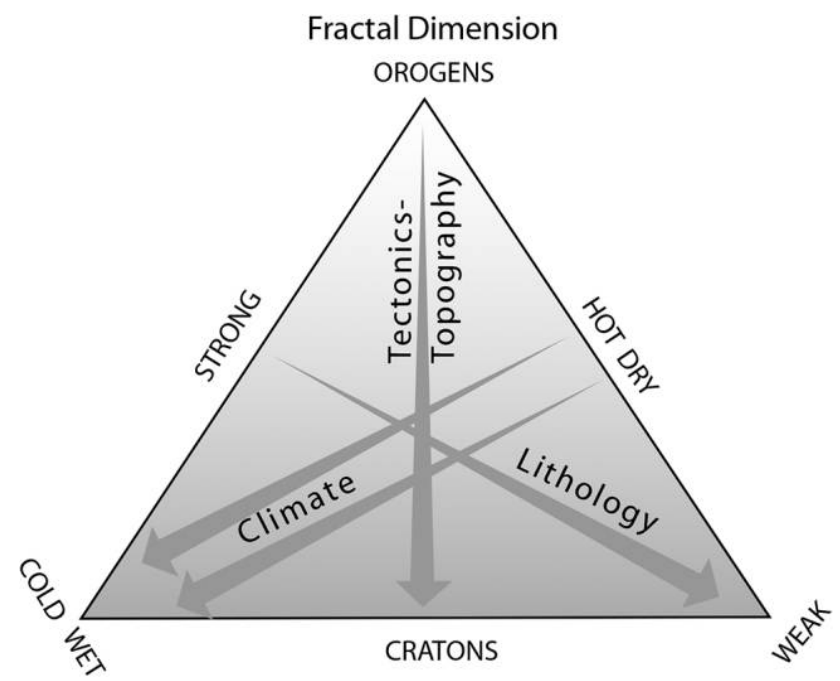

Figure 14. Ternary representation of the possible impact of tectonics, climate, and substrate lithology on the fractal dimension of weathered materials. Arrow directions show an increase in fractal dimension.

types present in eroding catchments. The effect of lithology on the fragmentation process can be seen from the disintegration of quartz-bearing igneous and metamorphic rocks (schists, gneisses) to produce quartz silt, whereas silt is deficient in the weathering of fine-grained sedimentary and metamorphic rocks, such as shales, phyllites, and slates (Jefferson et al. 1997).

The coarse-end grain size released from catchments scales on rock mass strength (Selby 1980), which in turn varies according to bedrock geology. In the Italian catchments studied, rock mass strength calculated from Schmidt hammer tests was consistently higher in carbonate terrains than in regions underlain by sandstones and shales. Field estimates of uniaxial compressive strength (Hoek and Brown 1997) shows a variation of rock mass strength based on the degree of foliation and fracturing.

The fractal dimension generated by the comminution of rocks is an index of the irregularity of the grain size distribution of the granular material: the higher the value of $D_{\mathrm{f}}$, the greater the proportion of fine particles in the particle size distribution. Laboratory grinding experiments suggest that the fractal dimension should also increase with the time period of comminution. However, the fractal dimension stabilizes after a critical period of grinding: what this critical period is in nature is unknown, but the possibility exists that the fractal dimension recorded from sediment deposits may be an intrinsic property that is diagnostic of the fragmentation process. In the grinding experiment of a well-sorted shallow marine sand from the Lower Cretaceous of Leighton Buzzard, England, the fractal dimension converged over time at a value of 2.5 (Lu et al. 2003; Langroudi et al. 2014). Lower fractal dimensions, indicating relatively high proportions of large fragments, may result from tectonic uplift or seismic shaking triggering landslides or from reworking and sorting. Rapid export of newly generated scree, regolith, and debris cones in steep catchments is also expected to reduce the fractal dimension.

Physical disintegration cannot be realistically separated from chemical weathering. Taking both, there are trends in the intensity of physical and chemical weathering based on variations in average temperature and average rainfall (fig. 13). Strong physical weathering typifies the high latitudes of the subarctic and tundra under low temperatures and low to moderate rainfalls. Physical weathering is intermediate in humid continental settings where frost cracking takes place but is low in dry, hot desert climates with the exception of coastal deserts, where rates of salt weathering may be high (Goudie and Viles 2008). Chemical weathering generates clay minerals by the breakdown of silicate rocks. Consequently, we should expect size distributions enriched in fine fragments in regions of intense chemical weathering, such as the wet tropical zone influenced by monsoonal rainfall, and to a lesser extent in the dry to humid continental and subtropical regions. Sediments liberated from catchments in these climatic zones should have high fractal dimensions.

Considered broadly and provisionally, the likely fractal dimension of sediment supplied to basins can be estimated on the basis of the paleogeography, climate, and geology of the source region (fig. 14). However, much data compilation needs to be carried out so that these broad generalizations can be improved on or replaced.

Within the framework offered by fragmentation theory, it would now be valuable to search for field examples where a documented downstream pattern of grain size fractionation can be linked to a particular statistical distribution of grain size in the sediment supply and where the effects of a secular change in the grain size mix can be discerned in basin stratigraphy. Doing so will enable the predictive capability of numerical approaches to stratigraphic architectures to be tested.

\section{A C K N O W LED G M E N T S}

Fundamental research on sediment routing systems was initially generously supported by Statoil. Further 
doctoral studies by M. D'Arcy and D. Roda-Boluda under the supervision of A. C. Whittaker enabled the collection of new particle size data. Grain size data from Sicily were collected with the help of A. Norori-McCormac and F. Knight. J. J. Armitage conducted the model simulations during the tenure of a research fellowship from the Royal Astronomical Society. We are grateful for the helpful comments of reviewers B. Romans (Virginia Tech) and F. Schlunegger (Bern, Switzerland).

\section{REFERENCES CITED}

Allen, P. A., and Allen, J. R. 2013. Basin analysis: principles and application to petroleum play assessment (3rd ed.). Oxford, Wiley-Blackwell, $619 \mathrm{p}$.

Allen, P. A.; Michael, N. A.; D'Arcy, M.; Roda-Boluda, D.; Whittaker, A. C.; Duller, R. A.; and Armitage, J. J. 2015. Fractionation of grain size in terrestrial sediment routing systems. Basin Res., forthcoming.

Armitage, J. J.; Duller, R. A.; Dunkley Jones, T.; Whittaker, A. C.; and Allen, P. A. 2013. Temporal buffering of climate-driven sediment flux cycles by transient catchment response. Earth Planet. Sci. Lett. 369-370: 200-210.

Armitage, J. J.; Duller, R. A.; Whittaker, A. C.; and Allen, P. A. 2011. Transformation of tectonic and climatic signals from source to stratigraphy. Nat. Geosci. 4:231-235.

Attal, M., and Lave, J. 2009. Pebble abrasion during fluvial transport: experimental results and implications for the evolution of sediment load along rivers. I. Geophys. Res. 114:F04023. doi:10.1029/2009JF001328.

Barton, C. C., and LaPointe, P. R. 1995. Fractals in the Earth sciences. New York, Plenum.

Benn, D. I., and Gemmell, A. M. D. 2002. Fractal dimensions of diamictic particle-size distributions: simulations and evaluation. Bull. Geol. Soc. Am. 114:528532.

Billi, A., and Storti, F. 2004. Fractal distribution of particle size in carbonate cataclastic rock from the core of a regional strike-slip zone. Tectonophysics 384: 115-128.

Bitelli, M.; Campbell, G. S.; and Flury, M. 1999. Characterization of particle size distribution in soils with a fragmentation model. Soil Sci. Soc. Am. I. 63:782-788. doi:10.2136/sssaj1999.634782x.

Burt, T. P., and Allison, R. J. Sediment cascades. 2010. In Burt, T. P., and Allison, R. J., eds. Sediment cascades in the environment: an integrated approach. Chichester, Wiley, p. 1-15.

Crovelli, R. A., and Barton, C. C. 1993. Fractals and the Pareto distribution applied to petroleum accumulationsize distributions. In US Department of the Interior, US Geological Survey, Open File Report, vol. 91-18, $29 \mathrm{p}$.

Curran, D. R.; Shockey, D. A.; Seaman, L.; and Austin, M. 1977. Mechanisms and models of cratering in Earth media. In Roddy, D. J.; Pepin, R. O.; and Merrill, R. P., eds. Impact and explosion cratering. New York, Pergamon, p. 1057-1087.

Dohnanyi, J. S. 1969. Collisional model of asteroids and their debris. I. Geophys. Res. 74:2531-2554.
Duller, R. A.; Whittaker, A. C.; Fedele, J. J.; Springett, J.; Smithells, R.; and Allen, P. A. 2010. From grain size to tectonics. I. Geophys. Res. 115:F03022. doi:10.1029 /2009JF001495.

Fedele, J. J., and Paola, C. 2007. Similarity solutions for fluvial sediment fining by selective deposition. I. Geophys. Res. 112:F02038. doi:10.1029/2005JF000409.

Fujiwara, A.; Kamimoto, G.; and Tsukamoto, A. 1977. Destruction of basaltic bodies by high-velocity impact. Icarus 31:277-288.

Goudie, A. S., and Viles, H. 2008. Weathering processes and forms. In Burt, T. P.; Chorley, R. J.; Brunsden, D.; Cox, N. J.; and Goudie, A. S., eds. Quaternary and Recent processes and forms (History of the Study of Landforms or the Development of Gemorphology Vol. 4). London, Geological Society, p. 129-164.

Hartmann, W. K. 1969. Terrestrial, lunar, and interplanetary rock fragmentation. Icarus 10:201-213.

Hastings, H. M., and Sugihara, G. 1993. Fractals: a user's guide for the natural sciences. Oxford, Oxford Science.

Hellyer, B. 1971. Fragmentation of asteroids. II. Numerical calculations. Mon. Not. R. Astron. Soc. 154:279_ 291.

Hoek, E., and Brown, E. T. 1997. Practical estimates of rock mass strength. Int. I. Rock Mech. Mining Sci. 34/8:1165-1186.

Hooke, R. Le B., and Iverson, N. R. 1995. Grain-size distribution in subglacial tills: role of grain fracture. Geology 23:57-60.

Hou, C. M.; Liu, X. W.; Liang, S. Y.; and Chen, W. W. 2009. The application of loess grain size fractal dimension in regional classification by natural features for highways in China. J. Desert Res. 29:828-834.

Hyslip, J. P., and Vallejo, L. E. 1997. Fractal analysis of the roughness and size distribution of granular materials. Eng. Geol. 48:231-244.

Ibbeken, H. 1983. Jointed source rock and fluvial gravels controlled by Rosin's law: a grain-size study in Calabria, south Italy. J. Sediment. Petrol. 53:1213-1231.

Jefferson, I. F.; Jefferson, B. Q.; Assallay, A. M.; Rogers, C. D. F.; and Smalley, I. J. 1997. Crushing of quartz sand to products silt particles. Naturwissenschaften $84: 1-3$

Kaminski, E., and Jaupart, C. 1998. The size distribution of pyroclasts and the fragmentation sequence in explosive volcanic eruptions. J. Geophys. Res. 103:29,75929,779 .

Kranenburg, C. 1994. The fractal structure of cohesive aggregates. Estuar. Coast. Shelf Sci. 39:451-460. 
Krumbein, W. C. 1941. Measurement and geological significance of shape and roundness of sedimentary particles. I. Sediment. Petrol. 11:64-72.

Langroudi, A. A.; Jefferson, I.; O'Hara-Dhand, K.; and Smalley, I. 2014. Micromechanics of quartz sand breakage in a fractal context. Geomorphology 211:1-10. doi:10.1016/j.geomorph.2013.12.016.

Lu, P.; Jefferson, I. F.; Rosenbaum, M. S.; and Smalley, I. J. 2003. Fractal characteristics of loess formation: evidence from laboratory experiments. Eng. Geol. 69: 287-293.

Mandelbrot, B. B. 1966. Forecasts of future prices, unbiased markets, and "martingale" models. I. Bus. 39: 242-255 (important errata are in a subsequent issue of the same journal).

Martinez-Mena, M.; Deeks, L. K.; and Williams, A. G. 1999. An evaluation of a fragmentation fractal dimension technique to determine soil erodibility. Geoderma 90: 87-98. doi:10.1016/S0016-7061(98)00097-4.

McEwen, M. C.; Fessenden, F. W.; and Rogers, J. J. W. 1959. Texture and composition of some weathered granites and slightly transported arkosic sands. I. Sediment. Petrol. 29:477-492.

Michael, N. A.; Whittaker, A. C.; and Allen, P. A. 2013. The functioning of sediment routing systems using a mass balance approach: example from the Eocene of the southern Pyrenees. I. Geol. 121:581-606. doi:10 $.1086 / 673176$.

Michael, N. A.; Whittaker, A. C.; Carter, A.; and Allen, P. A. 2014. Volumetric budget and grain-size fractionation of a geological sediment routing system: Eocene Escanilla Formation, south-central Pyrenees. Bull. Geol. Soc. Am. 126:585-599. doi:10.1130/B30954.1.

Middleton, G. V. 1976. Hydraulic interpretation of sand size distributions. I. Geol. 84:405-426.

Paola, C., and Seal, R. 1995. Grain size patchiness as a cause of selective deposition and downsystem fining. Water Resour. Res. 31:1395-1407.

Perfect, E. 1997. Fractal models for the fragmentation of rocks and soils: a review. Engineering Geology 48:185-198. doi:10.1016/S0013-7952(97)00040-9.

Pizzuto, J. E. 1995. Downstream fining in a network of gravel-bedded rivers. Water Resour. Res. 31:753759. doi:10.1029/94WR02532.

Posadas, A. N. D.; Gimenez, D.; Bittelli, M.; Vaz, C. M. P.; and Flury, M. 1997. Multifractal characterization of soil particle-size distribution. Soil Sci. Soc. Am. I. 65: 1361-1367.

Pye, K. 1995. The nature, origin and accumulation of loess. Quat. Sci. Rev. 14:653-667.

Rice, S. 1999. The nature and controls on downstream fining within sedimentary links. I. Sediment. Res. 69: 653-667. doi:10.2110/jsr.69.32.

Robinson, R. A. J., and Slingerland, R. L. 1998. Origin of fluvial grain size trends in a foreland basin: the Pocono Formation on the central Appalachian Basin. I. Sediment. Res. 68:473-486.

Sammis, C. G., and Biegel, R. L. 1989. Fractals, fault-gouge, and friction. Pure Appl. Geophys. 131:255-271.
Sammis, C. G.; King, G.; and Biegel, R. L. 1987. The kinematics of gouge deformation. Pure Appl. Geophys. 125:777-812.

Sammis, C. G., and Steacy, S. J. 1995. Fractal fragmentation in crustal shear zones. In Barton, C., and la Pointe, P. R., eds. Fractals in the Earth sciences. New York, Plenum, p. 179-204.

Schlunegger, F., and Norton, K. P. 2015. Climate vs. tectonics: the competing roles of Late Oligocene warming and Alpine orogenesis in constructing alluvial fan megasequences in the North Alpine Foreland Basin. Basin Res. 27:230-245. doi:10.1111/bre.12070.

Schoutens, J. E. 1979. Empirical analysis of nuclear and high-explosive cratering and ejecta. In Nuclear geophysics sourcebook. IV-Part II, DNA 6501H-4-2. Washington, DC, Defense Nuclear Energy.

Schroeder, M. 1991. Fractals, chaos, power laws. New York, Freeman.

Selby, M. J. 1980. A rock mass strength classification for geomorphic purposes. Z. Geomorph. 24:31-51.

Simpson, G. D. H., and Schlunegger, F. 2003. Topographic evolution and morphology of surfaces evolving in response to coupled fluvial and hillslope sediment transport. J. Geophys. Res. 108:B6. doi:10.1029/2002JB002162.

Smalley, I. J.; Jefferson, I. F.; O'Hara-Dhand, K.; and Evans, R. D. 2006. An approach to the problem of loess deposit formation: some comments on the in situ or soil-eluvial hypothesis. Quat. Int. 152:101-117.

Smalley, I. J.; Kumar, R.; O'Hara-Dhand, K.; Jefferson, I. F.; and Evans, R. D. 2005. The formation of silt material for terrestrial sediments, particularly loess and dust. Sediment. Geol. 179:321-328.

Smith, B. J.; Wright, J. S.; and Whalley, W. B. 2002. Sources of non-glacial, loess-size quartz silt and the origins of desert loess. Earth Sci. Rev. 59:1-26.

Smith, T. R., and Bretherton, F. P. 1972. Stability and the conservation of mass in drainage basin evolution. Water Resour. Res. 8:1506-1529.

Somme, T. O.; Helland-Hansen, W.; Martinsen, O. J.; and Thurmond, J. B. 2009. Relationships between morphological and sedimentological parameters in sourceto-sink systems: a basis for predicting semi-quantitative characteristics in subsurface systems. Basin Res. 21: 361-388.

Sternberg, H. 1875. Untersuchungen über Längen und Querprofil geschiebeführender Flüsse. Z. Bauwesen 25:483-506.

Strong, N.; Sheets, B. A.; Hickson, T. A.; and Paola, C. 2005. A mass balance framework for quantifying downstream changes in fluvial architecture (Fluvial Sedimentology VII Vol. 35). International Association of Sedimentologists Special Publication, p. 243253.

Tambo, N., and Watanabe, Y. 1979. Physical characteristics of flocs. I. The floc density function and aluminium floc. Water Res. 13:409-419.

Turcotte, D. L. 1997. Fractals and chaos in geology and geophysics (2nd ed.). Cambridge, Cambridge University Press. 
Tyler, S. W., and Wheatcraft, S. W. 1992. Fractal scaling of soil particle-size distributions: analysis and limitations. Soil Sci. Soc. Am. I. 56:362-369.

-1989. Application of fractal mathematics to soil water retention estimation. Soil Sci. Soc. Am. I. 53: 987-996.

Vidondo, B.; Prairie, Y. T.; Blanco, J. M.; and Duarte, C. M. 1997. Some aspects of the analysis of size spectra in aquatic ecology. Limnol. Oceanogr. 42:184192.

Wang, D.; Fu, B.; Zhao, W.; Hu, H.; and Wang, Y. 2008. Multifractal characteristics of soil particle size distribution under different land-use types on the Loess Plateau, China. Catena 72:29-36.

Wells, T.; Willgoose, G. R.; and Hancock, G. R. 2008. Modeling weathering pathways and processes of the frag- mentation of salt weathered quartz-chlorite schist. I. Geophys. Res. 113:F01014. doi:10.1029/2006JF000714.

Whittaker, A. C.; Attal, M.; and Allen, P. A. 2010. Characterising the origin, nature and fate of sediment exported from catchments perturbed by tectonics. Basin Res. 22:809-828. doi:10.1111/j.1365-2117.2009.00447.x.

Wright, J.; Smith, B.; and Whalley, B. 1998. Mechanisms of loess-sized quartz silt production and their relative effectiveness: laboratory simulations. Geomorphology 23:15-34.

Wu, Q.; Borkovee, M.; and Sticher, H. 1993. On particle size distributions in soils. Soil Sci. Soc. Am. I. 57:883890.

Wolman, M. G. 1954. A method of sampling coarse riverbed material. Trans. Am. Geophys. Union 35/6:951956. 